Atmos. Chem. Phys. Discuss., 7, 1295-1325, 2007

www.atmos-chem-phys-discuss.net/7/1295/2007/

(C) Author(s) 2007. This work is licensed

under a Creative Commons License.

Halos and ice crystals

T. J. Garrett et al.

\title{
Observing cirrus halos to constrain in-situ measurements of ice crystal size
}

\section{T. J. Garrett ${ }^{1}$, M. B. Kimball ${ }^{1}$, G. G. Mace ${ }^{1}$, and D. G. Baumgardner ${ }^{2}$}

${ }^{1}$ Department of Meteorology, University of Utah, Salt Lake City, UT, 84112-0110, USA

${ }^{2}$ Universidad Nacional Autonoma de Mexico, Mexico City, Mexico

Received: 21 December 2006 - Accepted: 16 January 2007 - Published: 26 January 2007

Correspondence to: T. Garrett (tgarrett@met.utah.edu)
Title Page
Abstract

Conclusions

Tables

14

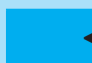

4

Back
Introduction

References

Figures

$>1$

$>$

Close
Full Screen / Esc

Printer-friendly Version

Interactive Discussion 


\section{Abstract}

In this study, characteristic optical sizes of ice crystals in synoptic cirrus are determined using airborne measurements of ice crystal size distributions, optical extinction and water content. The measurements are compared with coincident visual observations 5 of ice cloud optical phenomena, in particular the $22^{\circ}$ and $46^{\circ}$ halos. In general, the scattering profiles derived from the in-situ cloud probe measurements are consistent with the observed halo characteristics. It is argued that this implies that the measured ice crystals were small, probably with characteristic optical radii between 10 and $20 \mu \mathrm{m}$. There is a current contention that in-situ measurements of high concentrations of small ice crystals reflect artifacts from the shattering of large ice crystals on instrument inlets. Significant shattering cannot be entirely excluded using this approximate technique, but it is not indicated. On the basis of the in-situ measurements, a parameterization is provided that relates the optical effective radius of ice crystals to the temperature in mid-latitude synoptic cirrus.

\section{Introduction}

In cold clouds, the density in air of ice mass $(W)$ and optical extinction $\left(\beta_{\text {ext }}\right)$ is most usually related through an optical length scale termed the effective radius:

$r_{e}=\frac{3 W}{2 \rho_{i} \beta_{\mathrm{ext}}}$

where, $\rho_{i}$ is the bulk density of ice (Foot, 1988). Defined this way, $r_{e}$ represents the characteristic radius of an ensemble of hydrometeors, as represented by the ratio of their physical volume to their radiative extinction cross-section at visible wavelengths.

This paper examines the values of $r_{e}$ used for describing ensembles of ice crystals in numerical models of cirrus. The importance of correctly assessing the value of this parameter is that, as noted by Stephens et al. (1990), until it is well constrained, it is
Halos and ice crystals

T. J. Garrett et al.

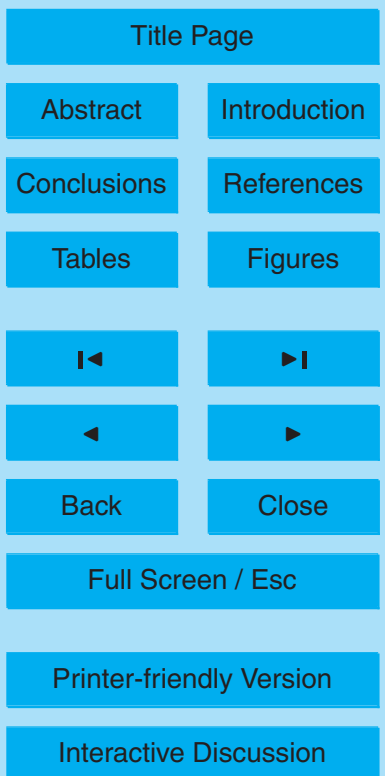


premature for climate models to predict even the sign of the cirrus-climate radiative feedback under a greenhouse warming scenario.

However, there is currently considerable disagreement within the cloud physics community as to which values of $r_{e}$ should be applied to simulated cirrus cloud. To illustrate, 5 measured values usually fall either in a range between 5 and $30 \mu \mathrm{m}$ (Heymsfield and Platt, 1984; Knollenberg et al., 1993; Boudala et al., 2002; Field et al., 2003; Gayet et al., 2004), or between 30 and $220 \mu \mathrm{m}$ (Dowling and Radke, 1990; Heymsfield and McFarquhar, 1996; Wyser, 1998; Baum et al., 2005; Field et al., 2005).

Within either range, there is variability due to natural variations in cirrus temperature 10 and ice water content IWC. Between the two ranges, however, the discrepancy can be attributed to differences in the interpretation of in-situ cloud probe data. The reliability of in-situ measurements of small ice crystals $<50 \mu \mathrm{m}$ across has been called in question. It has long been argued that larger ice crystals can shatter on the inlets of cloud probes, and produce artificially high concentrations of small ice crystals with large surface area et al., 2006).

While the importance of such shattering remains inconclusive, it is primarily for this reason that many studies have based their results on the measurement of ice crystals larger than 50 to $100 \mu \mathrm{m}$ across, choosing to omit or parameterize concentrations of ice crystals with smaller sizes. The studies that have observed generally smaller values of $r_{e}$ have included the full measured size spectrum, choosing instead to ignore the hypothesized influence of shattering.

Given that the conflicting evaluations point to near order of magnitude discrepancies, a more approximate, independent measurement technique may contribute to the debate about ice crystal size. Cirrus halos are ice crystal refractive phenomena seen as rings of enhanced scattering intensity around the sun. Cirrus optical phenomena have been used previously to argue for the presence of cubic ice in the earth's atmosphere (Riikonen et al., 2000). The characteristics of ice crystal halos yield may also information about ice crystal size (Fraser, 1979). Because they can be seen visually from

\section{Halos and ice crystals}

T. J. Garrett et al.

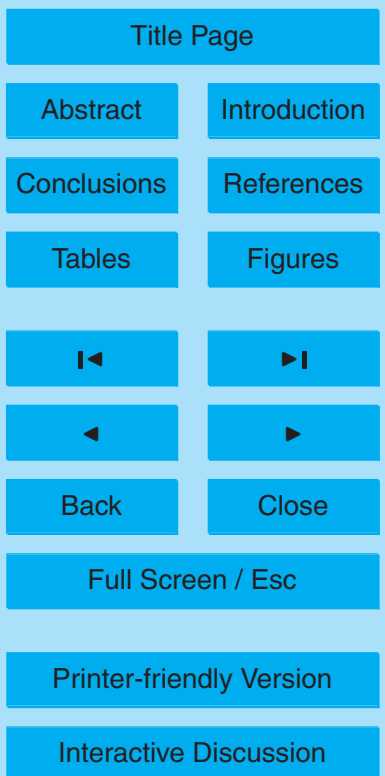

EGU 
within an aircraft cockpit, halo observations are obviously unaffected by shattering on instrument inlets.

We start by providing in Sect. 2 mostly theoretical arguments for the range of ice crystal sizes and cirrus optical depths that are conducive to production of halos. We 5 then proceed in Sect. 3 and 4 to examine the correspondence between theory and observations of halos and ice crystals from within cirrus. We use data from the NASA Mid-Latitude Cirrus Experiment (MidCiX), which took place over the central plains of the US and the Gulf of Mexico in April and May 2004. While flying in cirrus, the backseater in the WB-57F who operated special equipment noted cirrus optical effects.

10 The advantage to our study of using airborne observations is twofold: first the plane was capable of flying at high altitudes near cirrus cloud tops, where multiple-scattering contributions to observed downwelling radiances were low; second, cloud probes could measure the ice crystals within the same cloudy air that produced the observed optical effects. A summary is provided in Sect. 5.

\section{Criteria for halo formation}

In general, we are attempting to determine the angular intensity distribution / of visible solar radiation as it is transmitted downward through cirrus cloud

$I(\boldsymbol{\Omega})=\frac{\mu_{0} F_{\odot} T\left(\boldsymbol{\Omega}, \boldsymbol{\Omega}_{0}\right)}{\pi}$

where $T$ is the transmittance (unitless), $F_{\odot}$ is the solar constant, and $\Omega$ is a direction vector in a spherical co-ordinate system $\boldsymbol{\Omega}=(\mu, \phi)$ where $\mu$ is the angular cosine with respect to the nadir, and $\phi$ the azimuthal angle with respect to the direction of the incident solar beam. Subscript 0 is reserved for the solar nadir angle.

The function $T$ for a homogeneous cirrus layer is a function of its optical depth $\Delta \tau$ and the single-scattering phase function of the component ice crystals $P\left(\boldsymbol{\Omega}, \boldsymbol{\Omega}_{i}\right)$, where $\boldsymbol{\Omega}_{i}$ is the direction of an arbitrary incident beam. If it is assumed that the cirrus layer

Halos and ice crystals

T. J. Garrett et al.

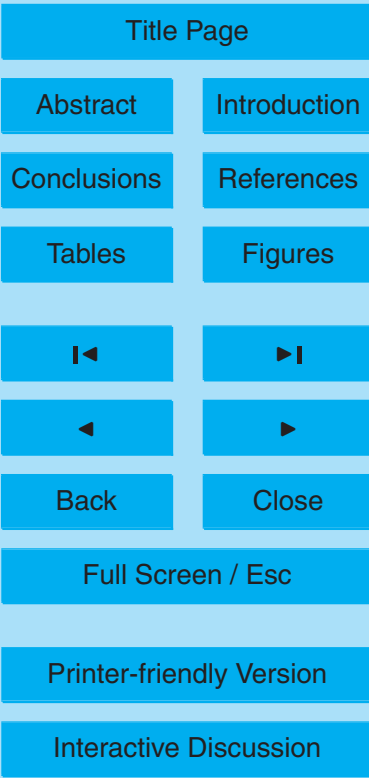


is optically thin, and that scattering is conservative (i.e. there is no absorption), a firstorder approximation for $T$ can be obtained through linearization of the radiative transfer equation and by equating $\boldsymbol{\Omega}_{i}$ to $\boldsymbol{\Omega}_{0}$ (Liou, 2002). In this paper, we focus specifically on the $22^{\circ}$ halo, which forms from refraction through two prism faces, and the $46^{\circ}$ halo, 5 which forms from refraction through a basal and a prism face. Respectively, the angular locations of the halos will be henceforth denoted as $\Delta \boldsymbol{\Omega}^{\prime}$ and $\Delta \boldsymbol{\Omega}^{\prime \prime}$ with respect to $\boldsymbol{\Omega}_{0}$,

$T\left(\boldsymbol{\Omega}_{0}+\Delta \boldsymbol{\Omega}, \boldsymbol{\Omega}_{0}\right)=\frac{P\left(\boldsymbol{\Omega}_{0}+\Delta \boldsymbol{\Omega}, \boldsymbol{\Omega}_{0}\right) \Delta \tau}{4 \mu \mu_{0}}$

Here, the phase function satisfies the normalization condition

$1=\frac{1}{4 \pi} \int_{0}^{4 \pi} P\left(\boldsymbol{\Omega}, \boldsymbol{\Omega}_{\mathrm{inc}}\right) d \Omega_{\mathrm{inc}}$

10 If more than one population of ice crystals is present (for example, from differing size ranges), the relative contributions to $T$ are proportional to the relative magnitudes of the column cross-sections, i.e.

$T\left(\boldsymbol{\Omega}_{0}+\Delta \boldsymbol{\Omega}, \boldsymbol{\Omega}_{0}\right)=\sum_{i} \frac{P_{i}\left(\boldsymbol{\Omega}_{0}+\Delta \boldsymbol{\Omega}, \boldsymbol{\Omega}_{0}\right) \Delta \tau_{i}}{4 \mu \mu_{0}}$

\subsection{Ice crystal size criteria}

15 First, we examine whether there exists a lower and upper bound to the size that ice crystals must have in order to form halos around the sun.

\subsubsection{Lower bound}

Ice crystals in cirrus cloud perturb the intensity field of visible sunlight through scattering. The refraction component can be well-approximated using ray-tracing, and creates displays of a variety of cirrus optical phenomena (Tape, 1994). Ice crystals also diffract

\section{ACPD}

7, 1295-1325, 2007

\section{Halos and ice} crystals

T. J. Garrett et al.

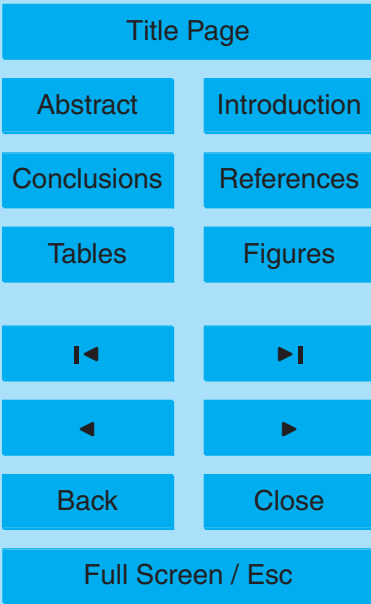

Printer-friendly Version

Interactive Discussion 
sunlight. If the crystals are sufficiently small, the diffraction can create a significant angular spread about the refractive angle of minimum deviation. For the $22^{\circ}$ or $46^{\circ}$ halos, the effective slit width is about about $37 \%$ of the dimension of the prism or basal face, respectively (Fraser, 1979). For simplicity, if we make the approximation that small 5 ice crystals are isometric and randomly oriented, with an "area equivalent" radius $r_{e q}$ (i.e. the radius of a circle with an equivalent geometric cross-section), then Fraunhofer diffraction is about an effective circular aperture with a radius $0.37 r_{e q} \cdot{ }^{1}$ Using analytic arguments described by Fraser (1979), the angular width from the central halo intensity peak to its half-power point is

$\theta_{1 / 2} \simeq \frac{\lambda}{2 r_{e q}}$

The approximate spread of a ray is thus $1^{\circ}$ for a $20 \mu \mathrm{m}$ equivalent radius crystal, and $4^{\circ}$ for a $5 \mu \mathrm{m}$ crystal.

Detailed ice crystal scattering phase functions that account for the spreading of the geometric optics ray have been calculated by Yang and Liou (1996) and Yang et al.

15 (2000). These show that, for randomly-oriented ice crystals, the smallest $r_{\text {eq }}$ conducive to sharply defined $22^{\circ}$ and $46^{\circ}$ halos is approximately $10 \mu \mathrm{m}$ (Fig. 1). Similar results have also been deduced with T-matrix calculations (Mishchenko and Macke, 1999) and in laboratory studies (Sassen and Liou, 1979).

\subsubsection{Upper bound}

20 The maximum ice crystal $r_{e q}$ associated with halo formation is determined by physics that is less fundamental, at least in the optical sense, and is therefore less well constrained.

\footnotetext{
${ }^{1}$ Based on geometric considerations, the area-equivalent radius of a solid, convex, randomly-oriented hexagonal ice crystal (van de Hulst, 1981) is typically 20 to $30 \%$ less than its effective radius, depending on the crystal size and aspect ratio.
}

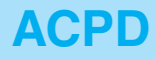

7, 1295-1325, 2007

\section{Halos and ice crystals}

T. J. Garrett et al.

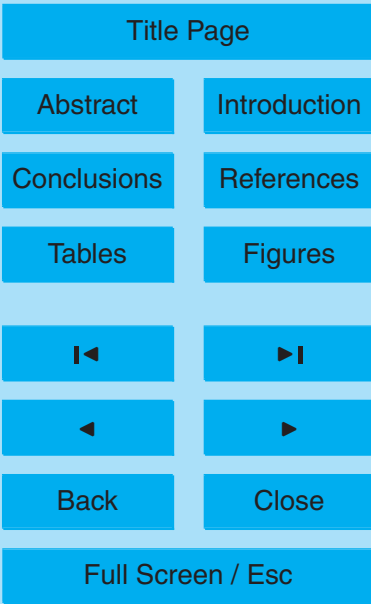

Printer-friendly Version

Interactive Discussion 
First, at the temperatures less than $-20^{\circ} \mathrm{C}$ found in cirrus, vapor tends to deposit preferentially on the basal face of ice crystals, favoring column growth (Kobayashi, 1961; Mason, 1994). While columns are nearly isometric at small sizes, they become increasingly elongated as $r_{e q}$ exceeds about $50 \mu \mathrm{m}$ (Auer and Veal, 1970). If 5 the columns are randomly oriented, the basal face forms an increasingly small fraction of surface area presented to an incoming ray. Because formation of a $46^{\circ}$ halo requires that a ray pass through a basal face, the reduced basal contribution to total surface area implies diminished $46^{\circ}$ halo intensity.

Pattloch and Tränkle (1984) argued that column crystals with aspect ratios $\leq 1 / 4$ 10 would produce only a $22^{\circ}$ halo. Thus, using as a guide the ice crystal aspect ratios observed by Auer and Veal (1970), the intensity of the $46^{\circ}$ halo is significantly diminished for columnar ice crystals with $r_{e q} \gtrsim 100 \mu \mathrm{m}$, for which the relative area contribution of the basal to prism facets is $\lesssim 10 \%$ (Note the relative halo peak heights in Fig. 1).

A second consideration is that, by definition, $P(\Delta \Omega)$ is at most a weak function of $\mu$ or ${ }_{15} \phi$ in a halo. For this to be true, the orientation of crystal facets with respect to the viewer should be nearly random. For individual ice crystals to fall with random orientation, they must be nearly isometric and have Reynolds numbers near unity, a property favored when $r_{e q} \lesssim 100 \mu \mathrm{m}$ (Sassen, 1980). There is some ambiguity however, because in some cases it may occur that clusters or mixtures of ice crystals produce random facet orientation, while being large enought to have oriented ice crystal descent (Fraser, 1979; Sassen et al., 1994; Tape, 1994). An example is bullet rosette ice crystals, or combinations of tilted columns and plates.

Finally, while ice crystals in their initial stages of growth tend to be pristine, continued growth favors irregularity. Halo intensities erode when bubbles develop in larger ice crystals (Mischchenko and Macke, 1997). Also, in a nearly saturated environment, periodic exposure to evaporation results in a pitted surface; in a supersaturated environment, growth is favored along ice crystal corners and edges where vapor gradients are highest (Pruppacher and Klett, 1997). Where edge growth is favored, facets become hollowed, eroding the canonical $60^{\circ}$ and $90^{\circ}$ crystal angles required for $22^{\circ}$ and

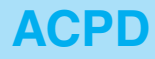

7, 1295-1325, 2007

\section{Halos and ice crystals}

T. J. Garrett et al.

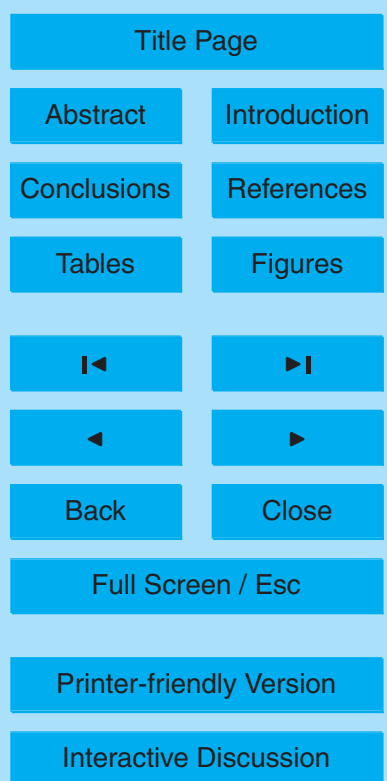

EGU 
$46^{\circ}$ halo formation.

It could be argued that canonical facet angles are maintained nevertheless. Ice crystals grow in microscopic steps, with heights between $0.01 \mu \mathrm{m}$ and $0.2 \mu \mathrm{m}$, that propagate across the ice crystal surface; when these steps bunch together they become 5 microscopically visible. Thereby, hollowed ice crystal facets can take on a step-like "hopper" structure (Pruppacher and Klett, 1997). Can these larger steps themselves produce halos? For diffractive effects not to dominate, such steps would need to exceed about $20 \mu \mathrm{m}$ in dimension. This seems unlikely as, to house such a hopper structure, the ice crystals themselves would need to be very large.

10 There is some observational support for the existence of an upper size limit. Bailey and Hallett (2002) found that pristine shapes are rarely found in the laboratory when $r_{e q} \gtrsim 100 \mu \mathrm{m}$. Tape (1994) has noted that atmospheric ice crystals must be both perfect and planar to produce halos. In mid-latitude cirrus uncinus, Auriol et al. (2001) observed no correspondence between the characteristics of ice crystals larger than $15100 \mu \mathrm{m}$, and the presence or absence of halo features as revealed by in-situ measurements of ice crystal phase functions.

\subsection{Optical depth criteria}

A second important consideration for determining halo production is cloud optical thickness. Cloud must be sufficiently thick to produce a distinguishable scattering signature, but not so thick that multiple-scattering obscures the single-scattering details of the phase function.

\subsubsection{Lower bound}

To produce a visible halo, the optical depth of a cirrus cloud must be sufficient that the scattering contribution from the cloud to $/\left(\boldsymbol{\Omega}_{0}+\Delta \boldsymbol{\Omega}\right)$ exceeds that from the clear-sky.

${ }_{25}$ Effectively then, what is required is that $T_{\text {cirrus }}\left(\boldsymbol{\Omega}_{0}+\Delta \boldsymbol{\Omega}, \boldsymbol{\Omega}_{0}\right)>T_{\text {clear sky }}\left(\boldsymbol{\Omega}_{0}+\Delta \boldsymbol{\Omega}, \boldsymbol{\Omega}_{0}\right)$. In the absence of aerosols, Rayleigh scattering by air is the only contributor to the

Halos and ice crystals

T. J. Garrett et al.

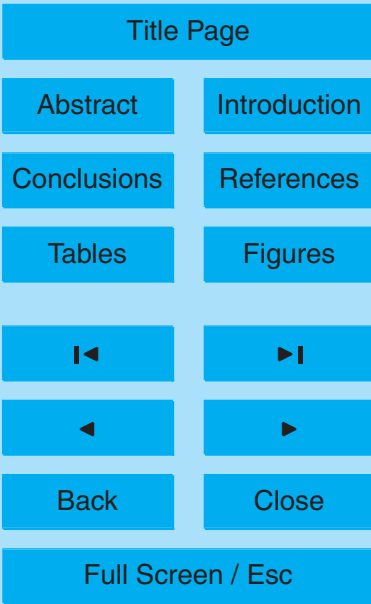

Printer-friendly Version

Interactive Discussion 
background signature. In this case, for fixed nadir angle, and from Eq. (3)

$\Delta \tau_{\text {cirrus }}>\frac{P_{\text {Rayleigh }}(\phi)}{P_{\text {cirrus }}(\phi)} \Delta \tau_{\text {Rayleigh }}$

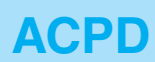

$7,1295-1325,2007$

To be conservative, we will consider the red $(0.65 \mu \mathrm{m})$ refracted component of a halo, because that is the color that is most easily visible above a predominantly blue sky.

5 The Rayleigh scattering phase function is well defined by

$P(\phi)=\frac{3}{4}\left(1+\cos ^{2} \phi\right)$

and the optical depth at visible wavelengths can be approximated by Dutton et al. (1994).

$\Delta \tau_{\text {Rayleigh }}=\frac{p}{p_{s}} 0.00877 \lambda^{-4.05}$

10 where, $\lambda$ is the wavelength (in $\mu \mathrm{m}$ ) and $p$ and $p_{s}$ are the pressure and surface pressure $(1013 \mathrm{hPa})$, respectively. For $r_{e q}=16 \mu \mathrm{m}$ column crystals, an optical depth $\Delta \tau_{\text {cirrus }}$ of 0.04 is required for the intensity of a red $46^{\circ}$ halo to exceed the intensity of the clear sky. For the blue $46^{\circ}$ halo to be visible also $(\lambda=0.45 \mu \mathrm{m})$, the value is 0.2 . Because the $22^{\circ}$ halo is stronger, the cloud optical depth need not be as high. The respective 15 minimum values of $\Delta \tau_{\text {cirrus }}$ required are 0.01 and 0.06 . Of course, the required value of $\Delta \tau_{\text {cirrus }}$ also decreases in proportion to $p$, because the sky darkens.

We note that in an aerosol haze, a higher minimum value of $\Delta \tau_{\text {cirrus }}$ is required.

\subsubsection{Upper bound}

As cirrus optical depth increases, multiple-scattering washes out the halo ring by making solar transmission more diffuse. It is possible to identify an upper optical depth limit for halo production, without resorting to detailed calculations, by considering that there

\section{Halos and ice} crystals

T. J. Garrett et al.

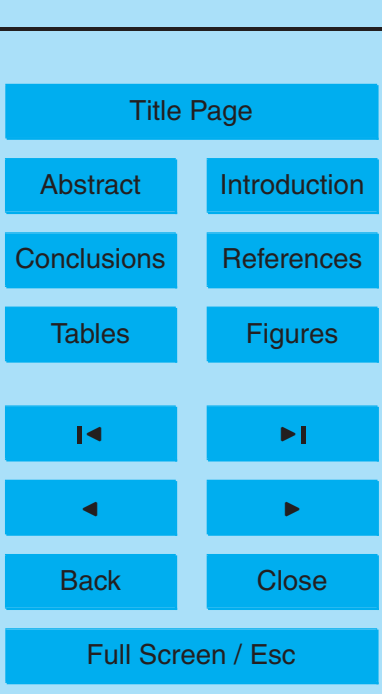

Printer-friendly Version

Interactive Discussion 
exists a hypothetical "diffusion domain" in which the intensity field is azimuthally symmetric (van de Hulst, 1980). King (1987) showed that if the diffusion limit is assumed, simplified radiative transfer calculations can yield calculated radiances that are accurate to within a few percent, provided the scaled optical depth $\tau^{\prime}=(1-g) \tau$ ( $g$ being 5 the asymmetry parameter) satisfies

$\tau^{\prime} \gtrsim 1$

In-situ measurements indicate that $g$ in extra-tropical cirrus is $0.75 \pm 0.03$ (Auriol et al., 2001; Garrett et al., 2001, 2003). Therefore, because the presence of a halo implies azimuthal asymmetry (unless the sun is directly overhead), Eq. (9) implies $\tau$ must be less than 4 for a halo to be visible. This result is closely confirmed by exact multiplescattering calculations using a doubling-adding technique (Takano and Liou, 1989).

In summary, with certain caveats, halo formation is favored by cirrus ice crystals with values of $r_{e q}$ that are larger than $10 \mu \mathrm{m}$ and smaller than $100 \mu \mathrm{m}$. The cirrus optical depth must be less than about 4 , but greater than at least 0.2 for full color separation to be visible from the ground. Smaller optical depths are required at lower atmospheric pressures. In our description of the observations that follows, we will consider both the $22^{\circ}$ and $46^{\circ}$ halos, but focus primarily on the latter. This is because it is weaker, so the requirements for its formation are more stringent.

\section{Observations}

\subsection{Instrumentation}

MidCiX consisted of 9 NASA WB-57F flights from Ellington field in Houston, Texas between 19 April and 6 May 2004. Airborne observations were made primarily within synoptic cirrus in moist outflow from the Gulf of Mexico. The WB-57F was equipped with a wide variety of cloud probes designed to measure ice particle characteristics

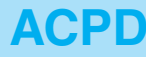

7, 1295-1325, 2007

\section{Halos and ice} crystals

T. J. Garrett et al.

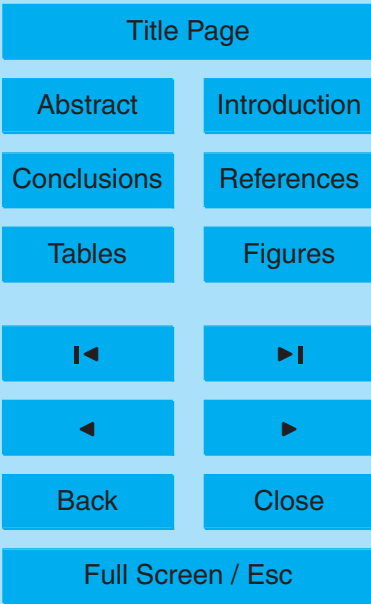

Printer-friendly Version

Interactive Discussion 
using a similar configuration to that employed during the more extensive CRYSTALFACE project that was based from southern Florida in 2002 (Jensen et al., 2004).

Cloud particle size distributions were obtained with a Cloud Aerosol and Precipitation Spectrometer (CAPS). The CAPS contains two size distribution probes, the Cloud and

5 Aerosol Spectrometer (CAS) and the Cloud Imaging Probe (CIP) which collectively measured particles between 0.5 and $1600 \mu \mathrm{m}$ across (Baumgardner et al., 2002). The CIP images ice crystal cross-sections directly, whereas the CAS infers crystal length from the intensity of forward scattering. For the sake of this study, we inferred ice crystal $r_{e q}$ assuming that CAS ice crystals $(<50 \mu \mathrm{m})$ were spherical, and inferred CIP $10 r_{e q}$ directly from the measured cross-sections.

Bulk measurements of the optical extinction coefficient $\beta_{\text {ext }}$ were obtained from the Cloud Integrating Nephelometer or CIN (Gerber et al., 2000). A remarkable outcome of MidCiX was the agreement between $\beta_{\text {ext }}$ derived from CAPS number concentration distributions of $n\left(r_{e q}\right)$ and $\beta_{\text {ext }}$ measured more directly from the CIN (Fig. 2). Heymsfield 15 et al. (2006) has argued that, like the CAPS probe, the CIN is affected by ice crystal shattering, and substantially overestimates $\beta_{\text {ext }}$ (although Garrett (2006) and Gerber (2006) describe why this is likely untrue). It cannot be ruled out that the agreement between the CIN and the CAPS was fortuitous, and that both probes were affected equally by ice crystal shattering. This would be surprising, however, given both probes had very different inlet structures and placements on the aircraft (in front of the wing for the CAPS and beneath the opposite wing for the CIN).

Bulk measurements of ice water content IWC were obtained by three probes aboard the WB-57F, all of which agreed to within $20 \%{ }^{2}$. Here we present data from the Harvard water probe (Weinstock et al., 1994). Through Eq. (1) values of CIN extinction coefficient and Harvard water content are combined to calculate $r_{e}$.

\footnotetext{
${ }^{2}$ Davis, S. M., Avallone, L. M., Weinstock, E. M., Twohy, C. H., Smith, J. B., and Kok, G. L.: Comparisons of in-situ measurements of cirrus cloud ice water content, J. Geophys. Res., in review, 2007.
}

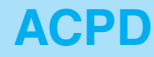

7, 1295-1325, 2007

\section{Halos and ice crystals}

T. J. Garrett et al.

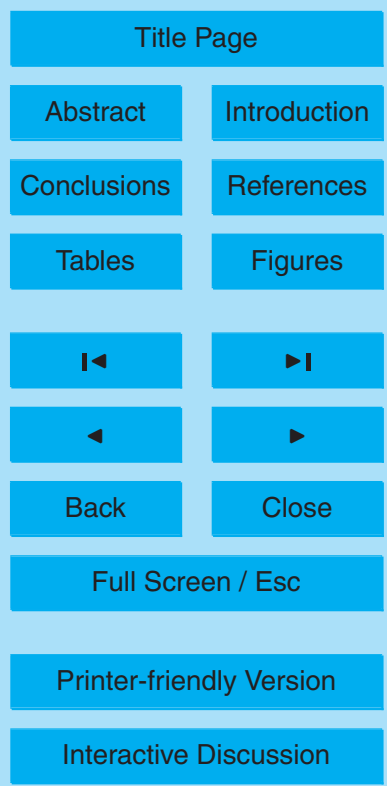




\subsection{Observations}

Prior to the MidCiX experiment, the back-seater on the WB-57F (B. Barnett), was given instruction on elementary aspects of halo observation, including how to manually estimate angular distance in the sky. He estimated that halos of some form were present

5 about one half of the time the WB-57F was both in cloud and near cloud-top. At the time, this observation came as a surprise, as halos are observed only infrequently from the ground. Particularly unexpected was that the back-seater often noted the rarely seen $46^{\circ}$ halo.

From all in-cloud flight during MidCiX, the back-seater explicitly registered the times 10 of $22^{\circ}$ halos on 20 occasions, of which 5 included a $46^{\circ}$ halo (e.g. Fig. 5). On one additional occasion, only a $46^{\circ}$ halo was observed, perhaps because cloud was not present at $22^{\circ}$ from the sun. For the time periods when $46^{\circ}$ halos were noted, the average measured temperature $T$ was $-42 \pm 6{ }^{\circ} \mathrm{C}$, the ice water content $0.019 \pm 0.014 \mathrm{~g}$ $\mathrm{m}^{-3}$, the extinction coefficient $1.7 \pm 1.1 \mathrm{~km}^{-1}$, and the effective radius was $15.2 \pm 4 \mu \mathrm{m}$.

15 For comparison, the averaged measured $T, I W C, \beta_{\text {ext }}$ and $r_{e}$ for all MidCiX cirrus (excluding orographic cirrus sampled on May 5) was $-47 \pm 9^{\circ} \mathrm{C}, 0.021 \pm 0.02 \mathrm{~g} \mathrm{~m}^{-3}$, $2.5 \pm 2.5 \mathrm{~km}^{-1}$, and $13.9 \pm 4.6 \mu \mathrm{m}$, respectively. The probability distributions of $\beta_{\text {ext }}$ in all cirrus and cirrus with $46^{\circ}$ halos noted is shown in Fig. 3.

Figure 4 shows the averaged normalized distributions of cross sectional area and number concentrations from the CAPS for the noted $46^{\circ}$ halo times and all MidCiX cirrus. In general, the shapes of the size distributions for the two data sets are similar, although halos generally were associated with somewhat warmer temperatures. Both sets of data display two distinct modes in the measured size distributions, a "small" mode at $r_{e q} \sim 10 \mu \mathrm{m}$ and a "large" mode at $r_{e q} \sim 100 \mu \mathrm{m}$. If the measurements are "correct", the small mode of ice crystals dominated the size distribution, and large mode particles, with $r_{e q}>25 \mu \mathrm{m}$, contributed just $4 \pm 4 \%$ to total extinction. The implication would be that the scattering signature produced by the cirrus was almost entirely dominated by very small ice crystals with $r_{e q} \sim 10 \mu \mathrm{m}$.

\section{Halos and ice crystals}

T. J. Garrett et al.

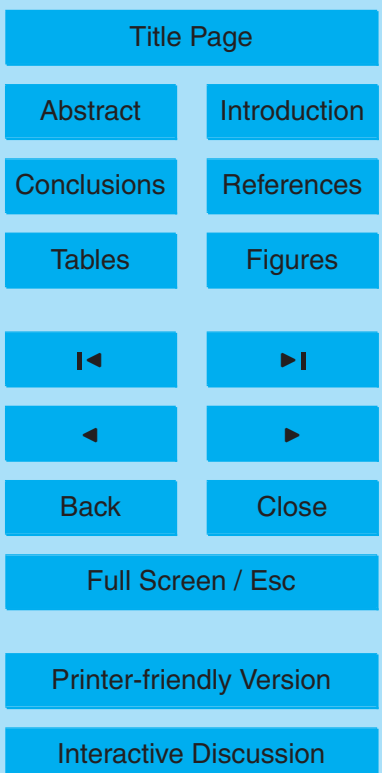




\subsection{Case Study}

Of course, it is possible that the small mode in the measured size and extinction distributions was largely or entirely a result of instrument artifacts from large ice crystal shattering. To evaluate this possibility we now look in detail at a particular example of

5 a halo measured during MidCiX, and compare the visual qualities of the halo to the in-situ measurements. Because halos are not subject to shattering artifacts, the goal is to evaluate for consistency. Of course, halo times represented only a subset of all cirrus measured. However, the size and extinction distributions of cirrus measured during "halo" times were similar to those measured when halos were not explicitly noted by the back-seater (Figs. 3 and 4). Thus, there are plausibly more general conclusions that may be drawn from this exercise.

As a case study, we examine in-situ measurements during a particularly striking halo display shown in Fig. 4, with both the $22^{\circ}$ and $46^{\circ}$ halos (Fig. 5). The photograph was taken from the WB-57F on 22 April 2004 at 19:00 UTC while the aircraft was flying 15 at $9.85 \mathrm{~km}$ altitude $\left(290 \mathrm{mb},-40^{\circ} \mathrm{C}\right)$ during an ascent through a cirrus deck over the Gulf of Mexico. It could be argued that the outer brightness band in Fig. 5 is in fact a supra-lateral arc (Tape, 1994). However, because the ray-path is the same for both phenomena, this is not an important consideration. In any case, a second photograph, taken at a lower angle around the same time, confirmed that the $46^{\circ}$ halo indeed formed 20 a circle. The measured $I W C, \beta_{\text {ext }}$ and $r_{e}$ for this time period were $0.018 \mathrm{~g} \mathrm{~m}^{-3}, 1.6 \mathrm{~km}^{-1}$ and $17.5 \mu \mathrm{m}$, respectively.

We begin by ignoring the multiple-scattering contribution to the intensity field shown in Fig. 5 on the premise that the halo is bright, and the blue sky is clearly visible through the cloud. In this case, the ice crystal phase function may be inferred from an intensity cross-section taken across the azimuth of the digital image (Fig. 6).

Some caution is needed here. While a digital image can cover a wide range of optical intensity, it does nonetheless saturate. Saturation implies asymptotically diminishing response with increasing intensity. Thus, for a given intensity range in the image, we

\section{Halos and ice crystals}

T. J. Garrett et al.

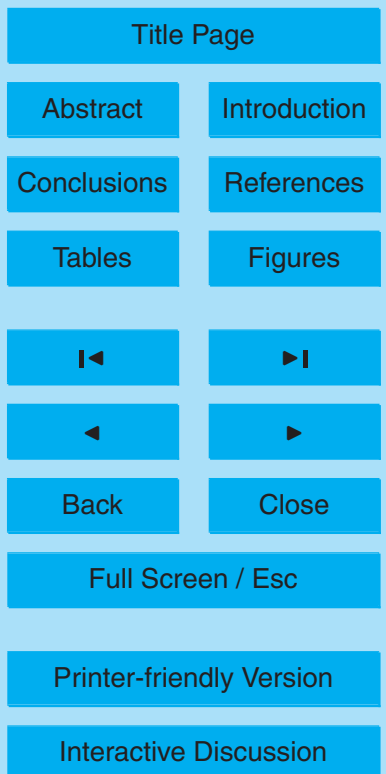


assume that relative intensities in the image scale with the logarithm of true relative intensities. The fitted scaling factor depends on the intensity range covered. Also we assume that the image accurately represents color.

Figure 6 shows intensity cross-sections of the image. The red and blue components 5 clearly show two halos at $22^{\circ}$ and $46^{\circ}$. For reference, we superimpose on the intensity figure a theoretical phase function for the scattering of red $(650 \mathrm{~nm})$ and blue $(475 \mathrm{~nm})$ light by column ice crystals with $r_{e q}=16 \mu \mathrm{m}$.

As a simplification, we can assume that, unless the cloud is extremely thin, the red halo intensity field dominates the red Rayleigh scattering field. Also, provided the o cloud is not thick (i.e. multiple-scattering is second-order), the red intensity field scales with the values of the red phase function. With these two assumptions, the relative intensities of the red $22^{\circ}$ and $46^{\circ}$ halos peaks $P_{\text {red }}\left(\phi^{\prime}\right) / P_{\text {red }}\left(\phi^{\prime \prime}\right)$ are 8.4 for $r_{e q}=16 \mu \mathrm{m}$ cyrstals and 14 for $r_{e q}=108 \mu \mathrm{m}$ crystals. Based on the image cross-section in Fig. 5, the corresponding image intensities for the two halos, $i\left(\phi^{\prime}\right)$ and $i\left(\phi^{\prime \prime}\right)$, are 0.86 and 150.67 , on a 0 to 1 scale. Thus, over this intensity range, $d i / d \ln P$ equals 0.09 and 0.07 for crystals with sizes $r_{e q}=16$ and $108 \mu \mathrm{m}$, respectively.

Next, some reference is required to convert the image pixel intensity ratio to a true image intensity. Here, we make the approximation that the blue intensity field at $\phi=41^{\circ}$ is dominated by the clear-sky Rayleigh-scattering signature. Note how the blue im20 age at this angle is much brighter $(i=0.64)$ than the red image $(i=0.46)$. For the date, time, and location of the image, the wavelength-integrated sky intensity in a blue band $(0.44 \mu \mathrm{m}$ to $0.52 \mu \mathrm{m})$ is $1.8 \mathrm{~W} \mathrm{~m}^{-2} \mathrm{sr}^{-1}$. From the aforementioned values for $d i / d \ln P$, and the peak $46^{\circ}$ halo image intensity $i=0.67$, we infer the wavelengthintegrated $(0.57 \mu \mathrm{m}$ to $0.69 \mu \mathrm{m})$ halo intensity in a red band $I_{\text {red }}\left(\phi^{\prime \prime}\right)$. The values are $252.5 \mathrm{~W} \mathrm{~m}^{-2} \mathrm{sr}^{-1}$ for $16 \mu \mathrm{m}$ crystals and $2.8 \mathrm{~W} \mathrm{~m}^{-2} \mathrm{sr}^{-1}$ for $108 \mu \mathrm{m}$ crystals.

By combining Eqs. (2) and (3), taking $\mu \equiv \mu_{0}$, and noting the associated wavelengthintegrated downwelling solar flux in the red band is $F_{\text {red } \odot}=187 \mathrm{~W} \mathrm{~m}^{-2}$, the optical depth

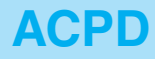

7, 1295-1325, 2007

\section{Halos and ice crystals}

T. J. Garrett et al.

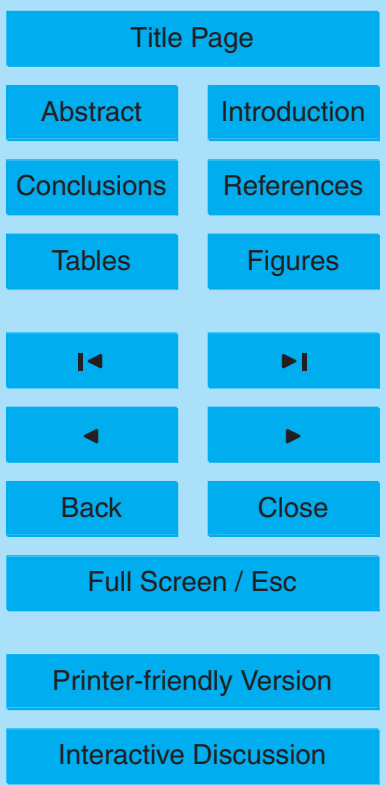


implied by the observed red intensity at the $46^{\circ}$ halo peak is then

$\Delta \tau=\frac{4 \pi \mu_{0} I_{\text {red }}\left(\phi^{\prime \prime}\right)}{P_{\text {red }}\left(\phi^{\prime \prime}\right) F_{\text {red } \odot}}$

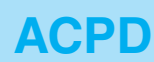

from which an approximate estimate of $\Delta \tau$ above the aircraft is 0.18 , independent of ice crystal size. The estimate lies within the lower and upper optical depth bounds 5 required for red halo formation, as described in Sect. 2.2.

Figure 5 was taken during a vertical profile of the cloud layer. Between the time of the photo and cloud top, the cloud properties were fairly homogeneous: both the CIN $\beta_{\text {ext }}$, and the CAPS relative contributions to $\beta_{\text {ext }}$ from large and small mode particles, had variability less than $50 \%$. Cloud top was reached at $10.05 \mathrm{~km}$, two minutes after

10 the photograph was taken, implying the depth of cloud $\Delta z$ that produced the halo was $200 \mathrm{~m}$.

The physical cloud depth above the aircraft can be also be deduced from the calculated value of $\Delta \tau$, if the value of $\beta_{\text {ext }}$ is known: in a homogeneous cloud layer, $\Delta \tau$ is the product of the extinction coefficient $\beta_{\text {ext }}$ and the layer depth $\Delta z$. We now compare 15 to the true value of $\Delta z$ the values of $\Delta z$ derived from the the contributions to $\beta_{\text {ext }}$ from the small and large modes, respectively (Fig. 4). In a 1 min window around the time of the photograph in Fig. 5, the measured contribution of the small mode of ice crystal particles $\left(r_{e q} \leq 25 \mu \mathrm{m}\right)$ to total $\beta_{\text {ext }}$ was $1.6 \mathrm{~km}^{-1}$, and from the large mode of particles $\left(r_{e q} \geq 25 \mu \mathrm{m}\right)$ it was $0.06 \mathrm{~km}^{-1}$.

20 First it is assumed that the small mode is real, and not solely the result of instrument artifacts. To account for the previously inferred halo optical depth of $\Delta \tau=0.18$, the corresponding estimate of cloud physical depth is $\Delta z \simeq 100 \mathrm{~m}$.

The second extreme is the limiting case where the measured small mode did not actually exist, and the halo was produced solely by large ice crystals. In this case, 25 large mode ice crystals need to have been dispersed through a cloud depth $\Delta z$ of about $5 \mathrm{~km}$ to account for the observed $46^{\circ}$ halo intensity. This would imply that the measured cirrus cloud extended into the stratosphere.

\section{Halos and ice} crystals

T. J. Garrett et al.

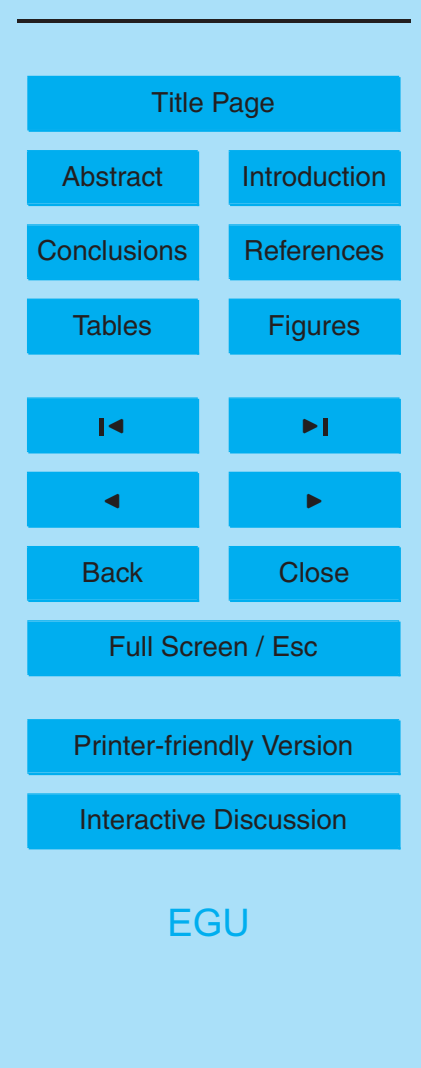


We emphasize that both estimates of $\Delta z$ are only very approximate, primarily due to the crude technique used to estimate $\Delta \tau$. However, optical extinction from the large ice crystals is more than an order of magnitude too small to reasonably account for the observed $46^{\circ}$ halo intensity. Only the estimate based on measurements of small mode 5 ice crystals is close.

An alternative way of looking at the problem is to consider that a blue halo was clearly visible at $\sim 46^{\circ}$ in Fig. 5, over and above the intensity of the blue sky. At the observed pressure of $290 \mathrm{mb}$, a cirrus optical depth greater than $\sim 0.1$ would have been required for the scattering profile of $\sim 100 \mu \mathrm{m} r_{e q}$ ice crystals (Fig. 1) to produce a blue halo 10 visible above the blue sky (see Sect. 2.2). Taking the actual measured cloud depth above the aircraft as $200 \mathrm{~m}$, and the measured large mode extinction coefficient to be $0.06 \mathrm{~km}^{-1}$, large ice crystals contributed to an optical depth of only about 0.01 . Again, this value is an order of magnitude too small.

We emphasize from this that these observations do not prove that the small mode as 15 measured by the CAPS probe was "correct", only that it is approximately consistent with the independent but approximate radiative quantities inferred from the halo photograph. What we can say with more confidence, however, is that the measured large mode did not produce the observed halo.

\section{Halos and effective radius parameterizations}

20 Ultimately, it is measurements of the effective radius $r_{e}$ that are of most interest to the cloud community, given their relevance to climate modeling. Here we examine in-situ measurements of $r_{e}$ in the context of simultaneous observations of halos. While the values of $r_{e q}$ and $r_{e}$ shown here should be similar, they are derived using different techniques. While values of $r_{e q}$ were derived from size distribution probes, values of ${ }_{25} r_{e}$ were derived from the ratio of bulk probe measurements of $I W C$ and $\beta_{\text {ext }}$.

Figure 7 shows the $r_{e}$ data from within MidCiX cirrus, together with a parameterized fit to the data. The instrumentation and techniques used during MidCiX for the calcu-

\section{Halos and ice crystals}

T. J. Garrett et al.

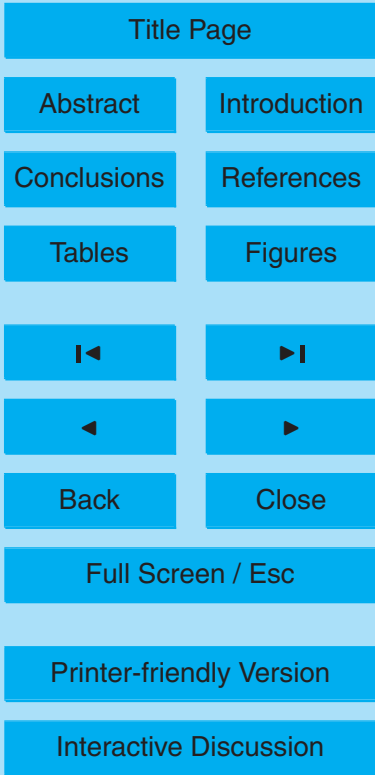


lation of $r_{e}$ were also applied by Garrett et al. (2003) to the CRYSTAL-FACE data set. CRYSTAL-FACE looked primarily at Florida deep convective anvils and tropopause cirrus aloft. A fit to the CRYSTAL-FACE data, as described by Garrett et al. (2003), is shown for comparison.

5 Both the MidCiX and CRYSTAL-FACE data sets show a similar exponential dependence on temperature, although for a given temperature, values of $r_{e}$ measured in MidCiX cirrus are generally about $50 \%$ higher than those from CRYSTAL-FACE. This difference may be physical, if it is considered that anvil cirrus ice crystals are homogeneously nucleated in convection under higher cooling rates (or equivalently, updraft 10 velocities) than those observed in synoptic cirrus. Correspondingly, condensate is distributed among a larger number of ice crystals, limiting individual ice crystal growth (Kärcher and Lohmann, 2002).

As described in Sect. 2.1, diffraction smooths out halos when the ice crystals are small. Consistent with this theoretical requirement, no $46^{\circ}$ halos were noted when 15 ice crystals were smaller than about $r_{e}=10 \mu \mathrm{m}$. The $46^{\circ}$ halo is relatively weak to begin with, so it may be particularly sensitive to diffraction. There were however a few observations of $22^{\circ}$ halos on 19 July, when the in-situ probes indicated values of $r_{e}$ as small as $8 \mu \mathrm{m}$.

At first glance, the association of very small values of $r_{e}$ with halos could be interpreted as implying that in-situ bulk probes, in particular the $\mathrm{CIN}$, overestimate concentrations of ice crystal extinction, perhaps due to shattering (Heymsfield et al., 2006). However, as particles get smaller, the transition from geometric to wave optics is not abrupt. Consider Fig. 8, which shows a photograph of a $22^{\circ}$ halo taken near cloud top during the time period when in-situ probes indicated effective radius values of $\simeq 8 \mu \mathrm{m}$.

25 The photograph is very similar to other halo photographs taken around the same time. Despite the photograph being taken near cloud top, the halo appears "washed-out", particularly compared to the example shown in Fig. 5. It displays no distinct boundaries or color separation. Also, there is no $46^{\circ}$ halo. In fact, the red intensity cross-section in Fig. 8 is similar to the scattering phase function for $7 \mu \mathrm{m}$ radius ice crystals (Fig. 1 ).

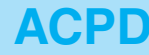

7, 1295-1325, 2007

\section{Halos and ice crystals}

T. J. Garrett et al.

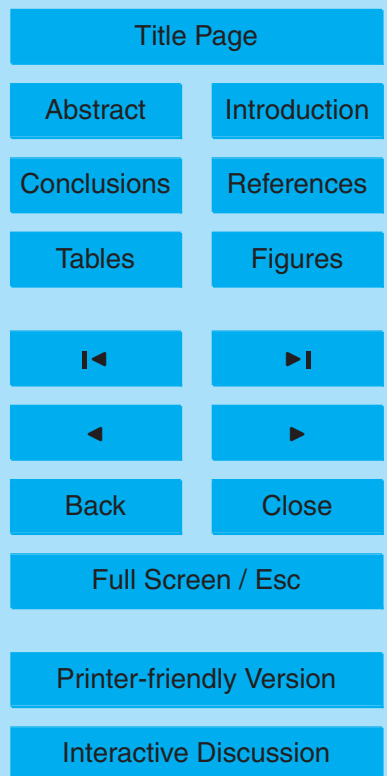

EGU 
Both show no $46^{\circ}$ halo and a broad intensity spread about $22^{\circ}$.

We cannot exclude the possibility that the CIN was affected to some degree by shattering. Nonetheless, the values of $r_{e}$ measured in-situ are qualitatively consistent with what was observed in coincident photography of ice crystal halos. The factor of 2 to 2.5 5 inflation of CIN measurements of $\beta_{\text {ext }}$ from shattering suggested by Heymsfield et al. (2006) seems unlikely, as it would suggest that halos get washed out below sizes much larger than required by theory.

\section{Summary}

The cloud physics community currently disagrees about the extent to which ice crystals smaller than $50 \mu \mathrm{m}$ across contribute to cloud optical properties. The reasons are largely due to concerns about artifacts produced from ice crystal shattering on cloud probe inlets. Here we have used observations of ice crystal halos from aboard an aircraft to provide an independent check on the validity of cloud probe measurements.

Ice crystal size distributions and bulk cloud properties in synoptic cirrus were measured from the WB-57F aircraft during the MidCIX experiment. There were no distinct differences between cloud properties measured when halos were explicitly noted, and those measured generally in cirrus. In particular, both data sets showed the presence of a bimodal size distribution. A "small" mode was centered at an area-equivalent radius $r_{e q} \simeq 16 \mu \mathrm{m}$, and a "large" mode was centered at $r_{e q} \simeq 100 \mu \mathrm{m}$. In general, the measured contribution to optical extinction $\beta_{\text {ext }}$ from the large
smaller than the measured contribution from the small mode.

We argued that a small mode of ice crystals must dominate optical extinction when the halos were observed for the following reasons:

- From aerodynamic, geometric, and depositional growth considerations, ice crystals larger than about $r_{e q}=100 \mu \mathrm{m}$ are not favored for halo formation.

- From a case study, the measured contribution to $\beta_{\text {ext }}$ from the large mode was 1312
7, 1295-1325, 2007

\section{Halos and ice crystals}

T. J. Garrett et al.

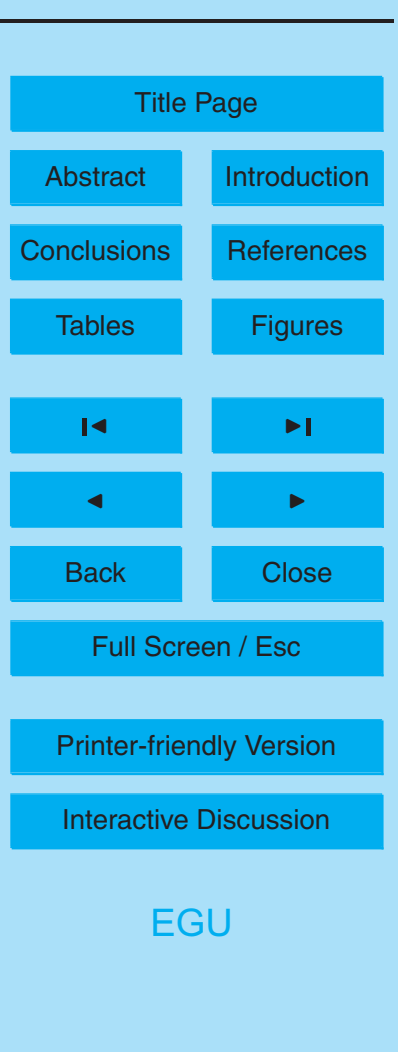


insufficient to account for the observed halo intensity, unless the physical depth of the cirrus sampled stretched well into the stratosphere, which it did not.

- From the same case study, a blue $46^{\circ}$ halo was observed that was brighter than the intensity of the blue sky background. To account for this, the contribution to $\beta_{\text {ext }}$ from the large mode was too small by an order of magnitude.

Times associated with halos were also compared with in-situ measurements of ice crystal effective radii $r_{e}$ measured using bulk extinction and ice water content probes. The measurements were consistent with theoretical interpretations of coincident halo observations. No $46^{\circ}$ halos were explicitly noted by the WB-57F back-seater when in10 situ measurements of ice crystal effective radii $r_{e}$ were smaller than about $10 \mu \mathrm{m}$. When the measured $r_{e}$ was as small as $8 \mu \mathrm{m}, 22^{\circ}$ halos were sometimes noted, but they lacked intensity and angular distinction. Diffraction spreads geometric rays at small ice crystal sizes. The optical effects are supportive of and consistent with effective radius parameterizations provided here and by Garrett et al. (2003).

15 Therefore, we see an encouraging consistency between the in-situ size distribution and extinction measurements of ice crystal particles, and the optical effects observed during MidCiX flight. We cannot exclude the possibility that the cloud-probe data were contaminated by shattering of large mode crystals on instrument inlets. However, to the extent shattering occured, it does not appear to have dominated the data, at least 20 nearer cloud top where halo observations were focused. What we can exclude is the possibility that optical dominance of a small mode can be generally ignored.

The picture we see has some similarities to that portrayed in the pioneering work of Heymsfield (1975): high concentrations of small ice crystals are nucleated in cirrus uncinus heads; much lower concentrations of larger crystals precipitate. It is worth noting that, from a climate standpoint, it is the crystal properties nearer cloud top that matter most. If satellite remote sensing or climate model parameterizations preclude the optical dominance of small mode ice crystals near cirrus tops, they risk missing important controlling physics. Of course, the generality of this conclusion remains to

Halos and ice crystals

T. J. Garrett et al.

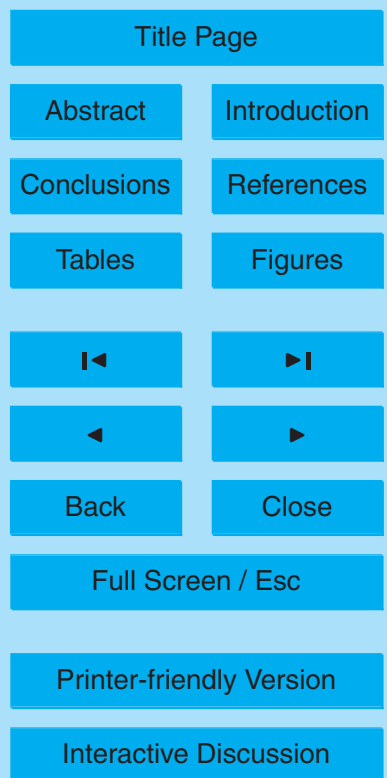

EGU 
be shown. We recommend that future airborne field programs make it a matter of practice to include photography of halo presence and absence.

Acknowledgements. This work was supported by grants NNX06AE24G through the NASA New Investigator Program, and NNG04GI68G through NASA Goddard. Appreciation to B. Barnett

5 for halo photography, E. M. Weinstock for water data, P. T. Bui for temperature data, Ping Yang for providing ice crystal phase functions, and helpful discussions with M. King.

\section{References}

Auer, A. H. and Veal, D. L.: The dimension of ice crystals in natural clouds, J. Atmos. Sci., 24, 919-926, 1970. 1301

10 Auriol, F., Gayet, J.-F., Febvre, G., Jourdan, O., Labonnote, L., and Brogniez, G.: In situ observation of cirrus scattering phase functions with 22 degree and 46 degree halos: Cloud field study on 19 February 1998, J. Atmos. Sci., 58, 3376-3390, 2001. 1302, 1304

Bailey, M. and Hallett, J.: Nucleation effects on the habit of vapour grown ice crystals from -18 to $-42{ }^{\circ} \mathrm{C}, \mathrm{Q}$. J. R. Meteorol. Soc., 128, 1461-1483, 2002. 1302

15 Baum, B. A., Heymsfield, A. J., Yang, P., and Bedka, S. T.: Bulk Scattering Properties for the Remote Sensing of Ice Clouds. Part I: Microphysical Data and Models., J. Appl. Meteorol., 44, 1885-1895, 2005. 1297

Baumgardner, D., Jonsson, H., Dawson, W., O'Connor, D., and Newton, R.: The cloud, aerosol and precipitation spectrometer (CAPS): A new instrument for cloud investigations, Atmos.

20 Res., 59-60, 251-264, 2002. 1305

Boudala, F. S., Isaac, G. A., Fu, Q., and Cober, S. G.: Paramaterization of effective ice particle size for high-altitude clouds, Int. J. Climatol., 22, 1267-1284, 2002. 1297

Dowling, D. R. and Radke, L. F.: A summary of the physical properties of cirrus clouds., J. Appl. Meteorol., 29, 970-978, 1990. 1297

Dutton, E. G., Reddy, P., Ryan, S., and DeLuisi, J. J.: Features and effects of aerosol optical depth observed at Mauna Loa, Hawaii, J. Geophys. Res., 99, 8295-8306, 1994. 1303

Field, P. R., Baran, A. J., Kaye, P. H., Hirst, E., and Greenaway, R.: A test of cirrus ice crystal scattering phase functions, Geophys. Res. Lett., 30, 7-1, 2003. 1297

Field, P. R., Wood, R., Brown, R. A., Kaye, P. H., Hirst, E., Greenway, R., and Smith, J. A.:

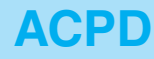

7, 1295-1325, 2007

Halos and ice crystals

T. J. Garrett et al.

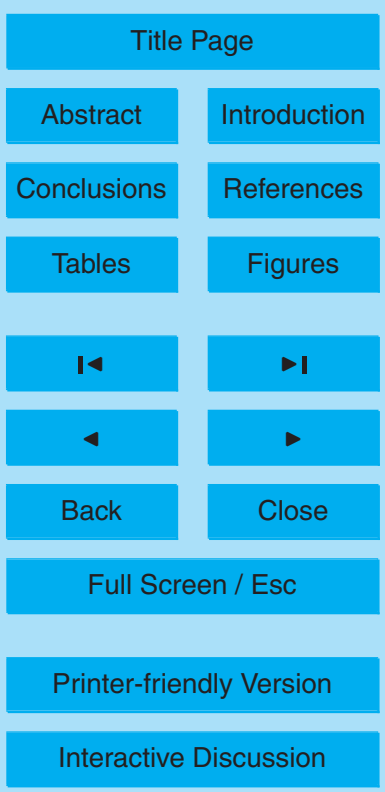


Ice particle interarrival times measured with a Fast FSSP, J. Atmos. Ocean. Technol., 20, 249-261, 2003. 1297

Field, P. R., Hogan, R. J., Brown, P. R. A., Illingworth, A. J., Choularton, T. W., and Cotton, R. J.: Parametrization of ice-particle size distributions for mid-latitude stratiform cloud, Q. J.

$5 \quad$ R. Meteor. Soc., 131, 1997-2017, 2005. 1297

Foot, J. S.: Some observations of the optical properties of clouds, Part 2, Cirrus, Q. J. R. Meteorol. Soc., 114, 145-164, 1988. 1296

Fraser, A. B.: What size of ice crystals causes halos?, J. Opt. Soc. Am., 69, 1112-1118, 1979. 1297, 1300, 1301

10 Gardiner, B. A. and Hallett, J.: Degradation of in-cloud forward scattering spectrometer probe measurements in the presence of ice particles, J. Atmos. Oceanic Technol., 2, 171-189, 1985. 1297

Garrett, T. J.: Comment on "Effective radius of ice cloud particle populations derived from aircraft probes" by Heymsfield et al., J. Atmos. Oceanic. Technol., accepted, 2006. 1305

15 Garrett, T. J., Hobbs, P. V., and Gerber, H.: Shortwave, single-scattering properties of arctic ice clouds, J. Geophys. Res., 106, 15 155-15172, 2001. 1304

Garrett, T. J., Gerber, H., Baumgardner, D. G., Twohy, C. H., and Weinstock, E. M.: Small, highly reflective ice crystals in low-latitude cirrus, Geophys. Res. Lett., 30, 2003. 1304, 1311, 1313, 1324

20 Gayet, J.-F., Febvre, G., and Larsen, H.: The reliability of the PMS FSSP in the presence of small ice crystals, J. Atmos. Oceanic. Technol., 13, 1300-1310, 1996. 1297

Gayet, J.-F., Ovarlez, J., Shcherbakov, V., Ström, J., Schumann, U., Minikin, A., Auriol, F., Petzold, A., and Monier, M.: Cirrus cloud microphysical and optical properties at southern and northern midlatitudes during the INCA experiment, J. Geophys. Res., 109, 2004. 1297

Gerber, H.: Comment on "Effective radius of ice cloud particle populations derived from aircraft probes" by Heymsfield et al., J. Atmos. Oceanic. Technol., accepted, 2006. 1305

Gerber, H., Takano, Y., Garrett, T. J., and Hobbs, P. V.: Nephelometer measurements of the asymmetry parameter, volume extinction coefficient, and backscatter ratio in clouds, J. Atmos. Sci., 57, 3021-3034, 2000. 1305

30 Heymsfield, A.: Cirrus Uncinus Generating Cells and the Evolution of Cirriform Clouds. Part I: Aircraft Observations of the Growth of the Ice Phase, J. Atmos. Sci., 32, 799-808, 1975. 1313

Heymsfield, A. J. and McFarquhar, G. M.: High albedos of cirrus in the tropical Pacific warm

\section{Halos and ice crystals}

T. J. Garrett et al.

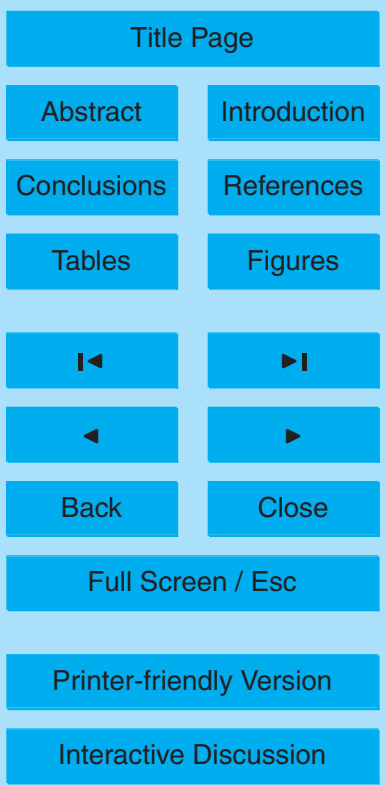

EGU 
pool: Microphysical interpretations from CEPEX and from Kwajelein, Marshall Islands, J. Atmos. Sci., 53, 2424-2451, 1996. 1297

Heymsfield, A. J. and Platt, C. M. R.: A Parameterization of the Particle Size Spectrum of Ice Clouds in Terms of the Ambient Temperature and the Ice Water Content., J. Atmos. Sci., 41, 846-855, 1984. 1297

Heymsfield, A. J., Schmitt, C., Bansemer, A., van Zadelhoff, G.-J., McGill, M. J., Twohy, C., and Baumgardner, D.: Effective radius of ice cloud particle populations derived from aircraft probes, J. Atmos. Oceanic. Technol., 23, 361-380, 2006. 1297, 1305, 1311, 1312

Jensen, E., Starr, D., and Toon, O. B.: Mission investigates tropical cirrus clouds, EOS, 84, 45-50, 2004. 1305

Kärcher, B. and Lohmann, U.: A parameterization of cirrus cloud formation: Homogeneous freezing including effects of aerosol size, J. Geophys. Res., 107, 2002. 1311

King, M.: Determination of the scaled optical thickness of clouds from reflected solar radiation measurements, J. Atmos. Sci., 44, 1734-1751, 1987. 1304

15 Knollenberg, R. G., Kelly, K., and Wilson, J. C.: Measurements of high number densities of ice crystals in the tops of tropical cumulonimbus, J. Geophys. Res., 98, 8639-8664, 1993. 1297

Kobayashi, T.: The growth of ice crystals at low supersaturations, Phil. Mag., 6, 1363-1370, 1961. 1301

Liou, K.: An Introduction to Atmospheric Radiation, International Geophysics Series, Academic Press, 2002. 1299

Mason, B. J.: The shape of snow crystals-Fitness for purpose?, Q. J. R. Meteor. Soc., 120, 849-860, 1994. 1301

Mischchenko, M. I. and Macke, A.: Asymmetry parameters of the phase function for isolated and densely packed spherical particles with multiple internal inclusions in the geometric optics limit, J. Quant. Spectrosc. Radiat. Transfer, 57, 767-794, 1997. 1301

Mishchenko, M. I. and Macke, A.: How big should hexagonal crystals be to produce halos?, Appl. Opt., 38, 1626-1629, 1999. 1300

Pattloch, F. and Tränkle, E.: Monte Carlo simulation and analysis of halo phenomena, J. Opt. Soc. Am. A, 1, 520-526, 1984. 1301

30 Pruppacher, H. R. and Klett, J. D.: Microphysics of Clouds and Precipitation, $2^{\text {nd }}$ Rev. Edn., Kluwer Academic Publishing, Dordrecht, 1997. 1301, 1302

Riikonen, M., Sillanpaa, M., Virta, L., Sullivan, D., Moilanen, J., and Luukkonen, I.: Halo observations provide evidence of airborne cubic ice in the Earth's atmosphere, Applied Optics, 39,

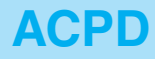

7, 1295-1325, 2007

\section{Halos and ice crystals}

T. J. Garrett et al.

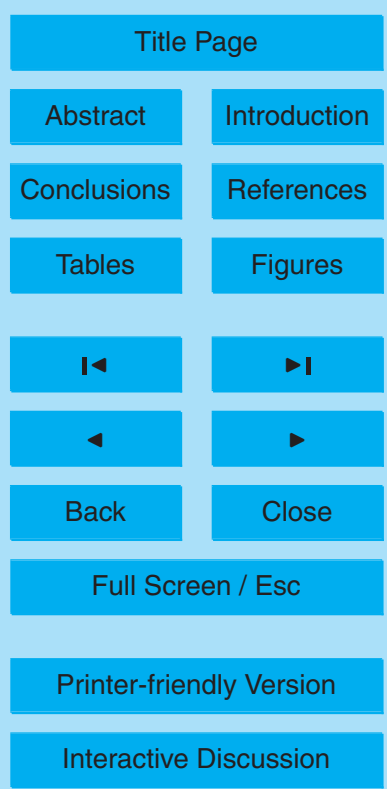


6080-6085, 2000. 1297

Sassen, K.: Remote Sensing of planar ice crystal fall attitudes, J. Meteor. Soc. Japan, 58, 422-429, 1980. 1301

Sassen, K. and Liou, K.-N.: Scattering of polarized laser light by water droplet, mixed-phase 5 and ice crystals clouds. Part I: Angular scattering patterns, J. Atmos. Sci., 36, 838-851, 1979. 1300

Sassen, K., Knight, N. C., Takano, Y., and Heymsfield, A. J.: Effects of ice-crystal structure on halo formation: cirrus cloud experimental and ray-tracing modeling studies, Appl. Opt., 33, 4590-4601, 1994. 1301

10 Stephens, G. L., Tsay, S.-C., Stackhouse Jr., P. W., and Flatau, P. J.: The relevance of the micropysical and radiative properties of cirrus clouds to climate and climate feedback, $\mathrm{J}$. Atmos. Sci., 47, 1742-1753, 1990. 1296

Takano, Y. and Liou, K.-N.: Solar radiative transfer in cirrus clouds. Part II: Theory and computation of multiple scattering in an anisotropic medium, J. Atmos. Sci., 46, 20-36, 1989. 151304

Tape, W.: Atmospheric Halos, Antarctic Research Series, 1994. 1299, 1301, 1302, 1307 van de Hulst, H. C.: Multiple Light Scattering, Tables, Formulas, and Applications, Academic Press, 1980. 1304

van de Hulst, H. C.: Light Scattering by Small Particles, Dover, 1981. 1300

20 Weinstock, E. M., Hintsa, E., Dessler, A., Oliver, J., Hazen, N., Demusz, J., Alien, N.T.and Lapson, L., and Anderson, J.: New fast response photofragment fluorescence hygrometer for use on the NASA ER-2 and the Perseus remotely piloted aircraft, Rev. Sci. Instrum., 65, 3544-3554, 1994. 1305

Wyser, K.: The Effective Radius in Ice Clouds., J. Climate, 11, 1793-1802, 1998. 1297

Yang, P. and Liou, K. N.: Geometric-optics-integral-equation method for light scattering by nonspherical ice crystals, Appl. Opt., 35, 6568-6584, 1996. 1300, 1318

Yang, P., Liou, K. N., Wyser, K., and Mitchell, D.: Parameterization of the scattering and absorption properties of individual ice crystals, J. Geophys. Res., 105, 4699-4718, 2000. 1300, 1318

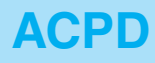

7, 1295-1325, 2007

\section{Halos and ice} crystals

T. J. Garrett et al.

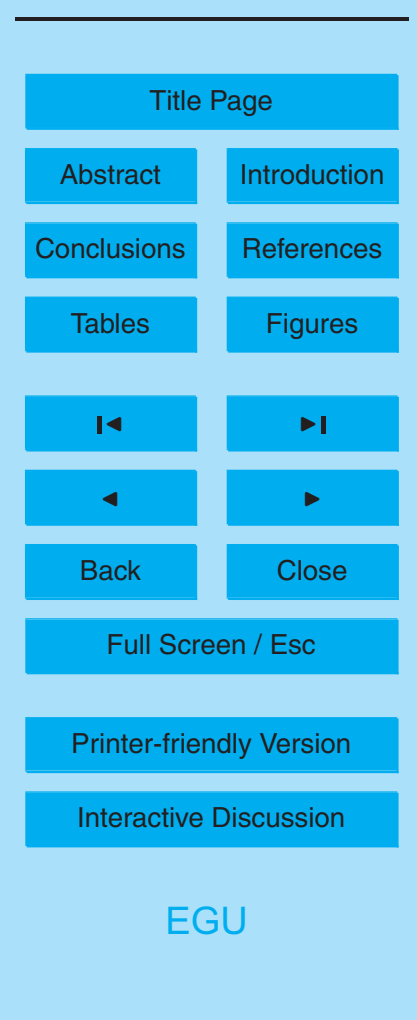




\section{ACPD}

$7,1295-1325,2007$

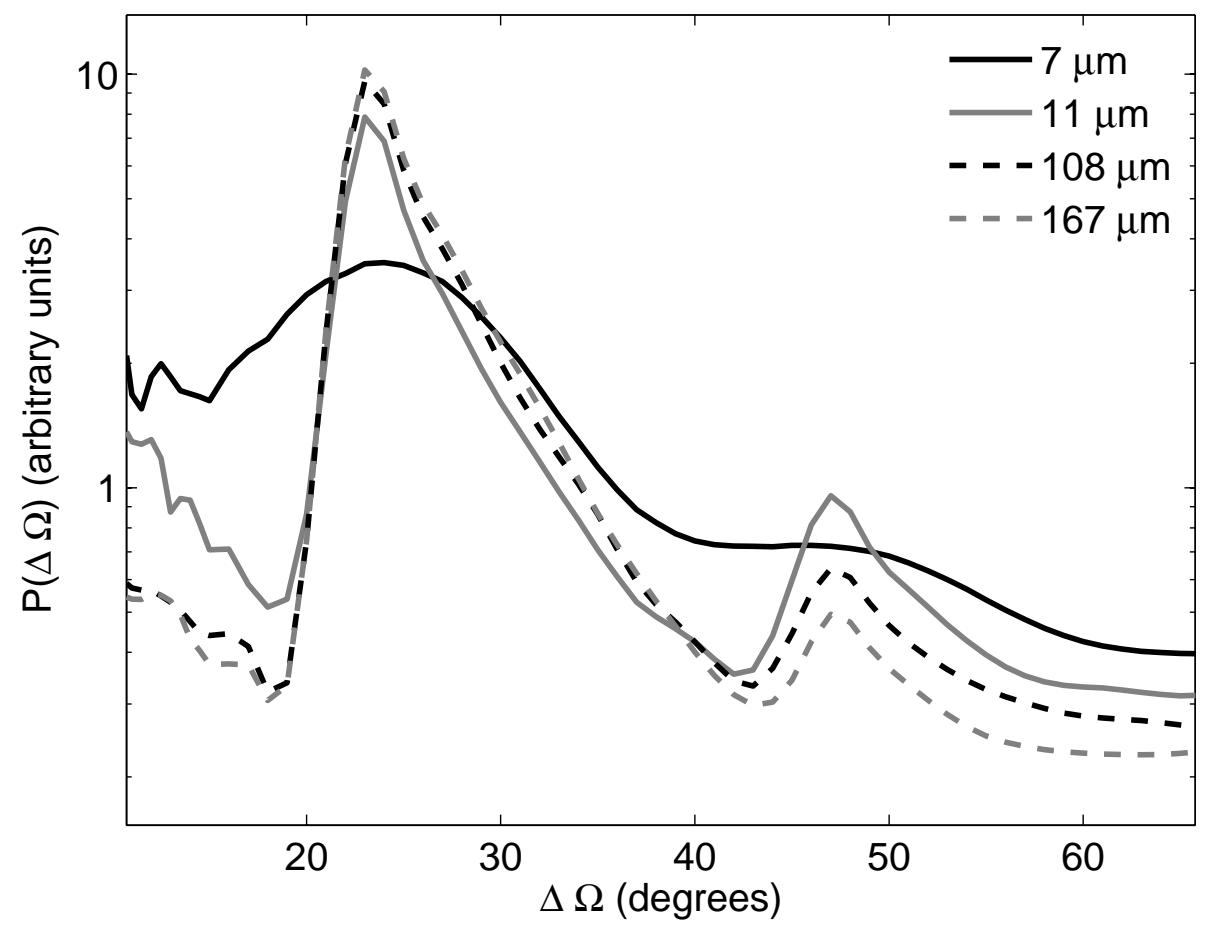

Fig. 1. Ice crystal scattering phase functions $P(\Delta \boldsymbol{\Omega})$ for column ice crystals of varying equivalent radii $r_{e q}$ (Yang and Liou, 1996; Yang et al., 2000).

\section{Halos and ice crystals}

T. J. Garrett et al.

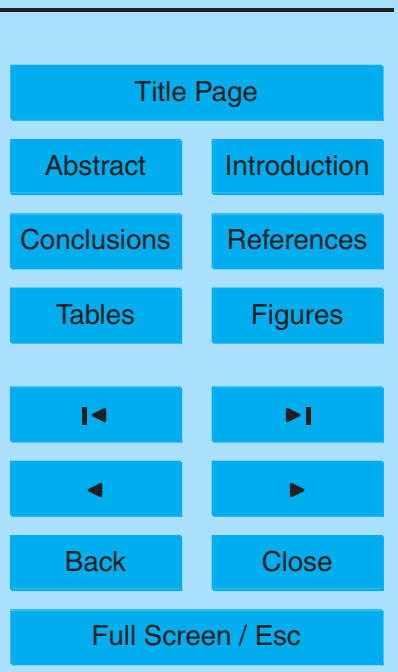

Printer-friendly Version

Interactive Discussion 


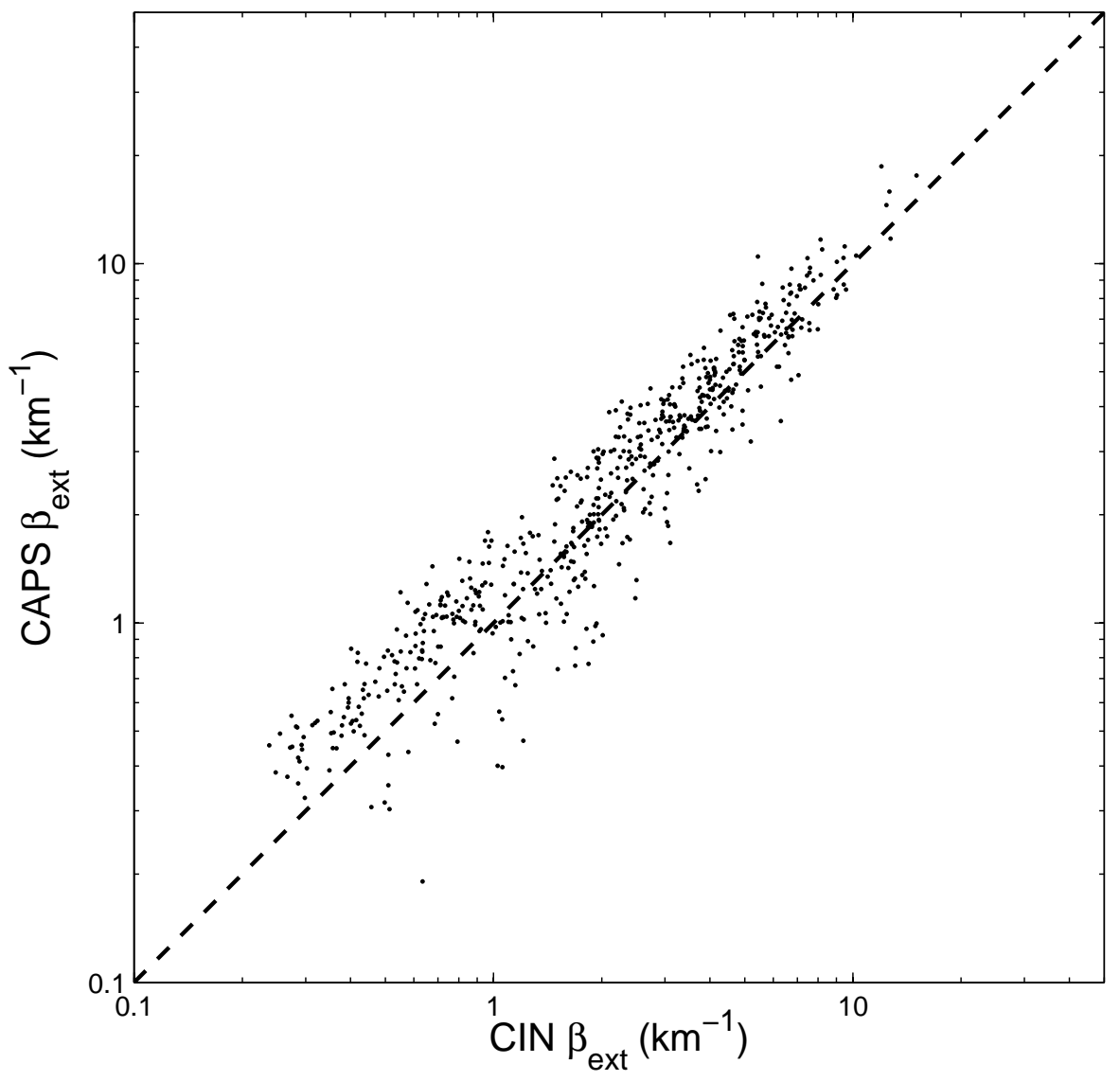

Fig. 2. Comparison of $\beta_{\text {ext }}$ derived from integrated projected area measurements from the CAPS, and bulk extinction measurements from the CIN.

\section{ACPD}

7, 1295-1325, 2007

Halos and ice crystals

T. J. Garrett et al.

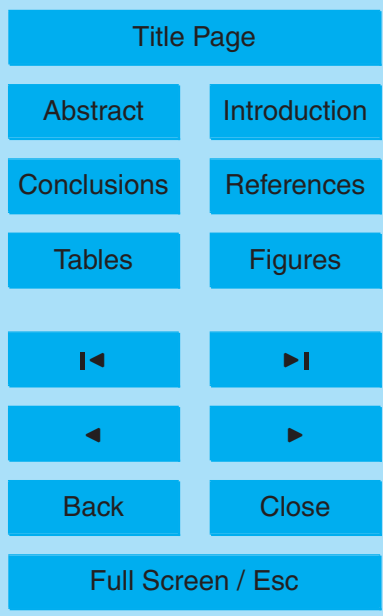

Printer-friendly Version

Interactive Discussion 


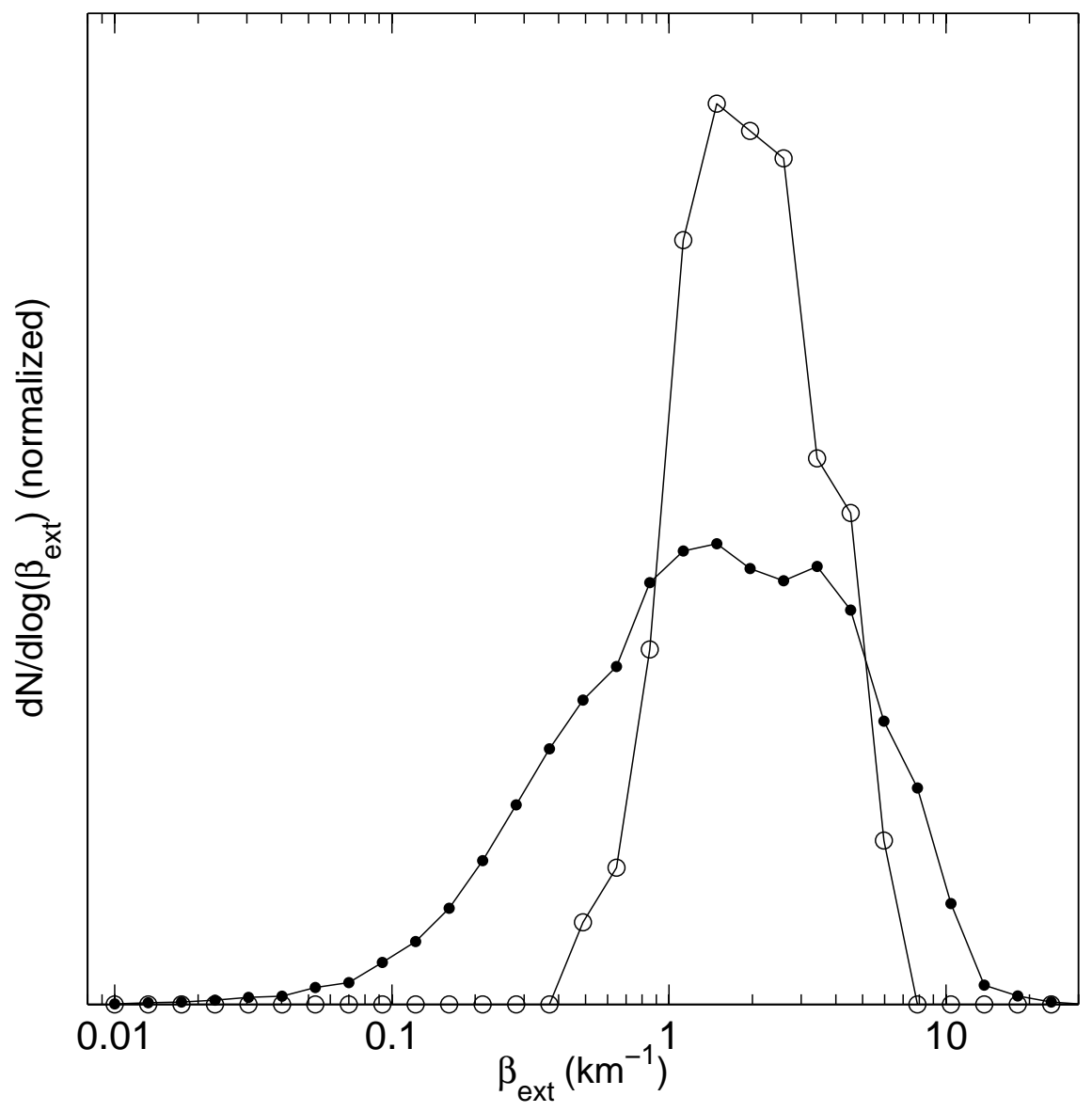

Fig. 3. Probability distributions of the extinction coefficient $\beta_{\text {ext }}$ measured with the CIN probe in all cirrus (solid) and cirrus when $46^{\circ}$ halos were explicitly noted (circles), during MidCiX.

\section{ACPD}

7, 1295-1325, 2007

\section{Halos and ice crystals}

T. J. Garrett et al.

\section{Title Page}

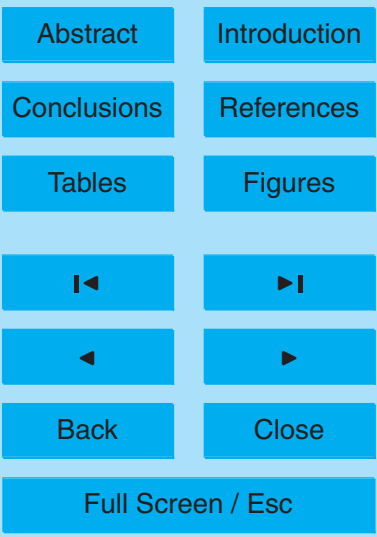

Printer-friendly Version

Interactive Discussion 


\section{ACPD}

$7,1295-1325,2007$
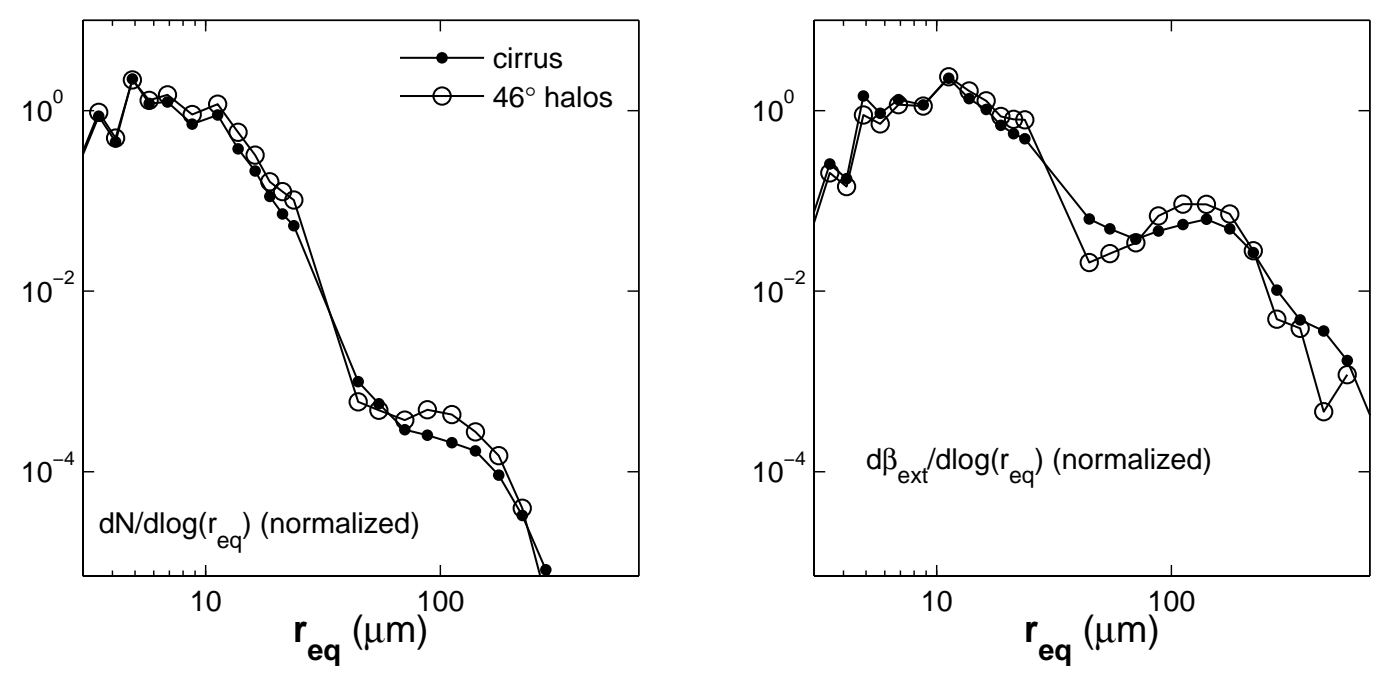

\section{Halos and ice} crystals

T. J. Garrett et al.

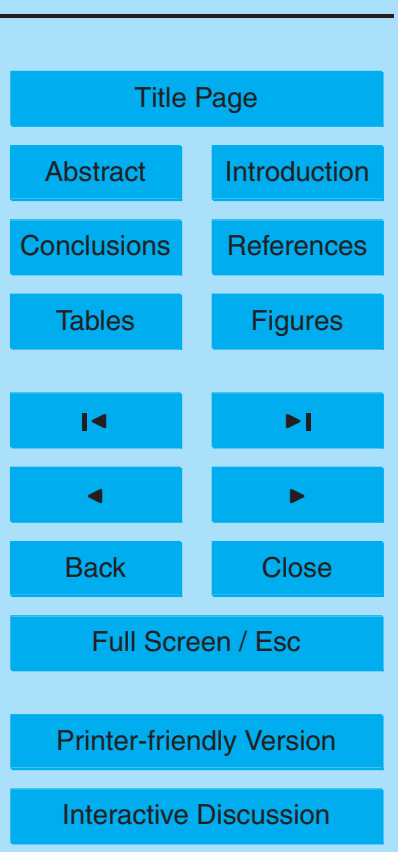

Fig. 4. Normalized number (left) and extinction coefficient (right) distributions measured by the CAPS probe in all cirrus (solid), and cirrus when $46^{\circ}$ halos were explicitly noted (circles), during MidCiX. 


\section{ACPD}

7, 1295-1325, 2007

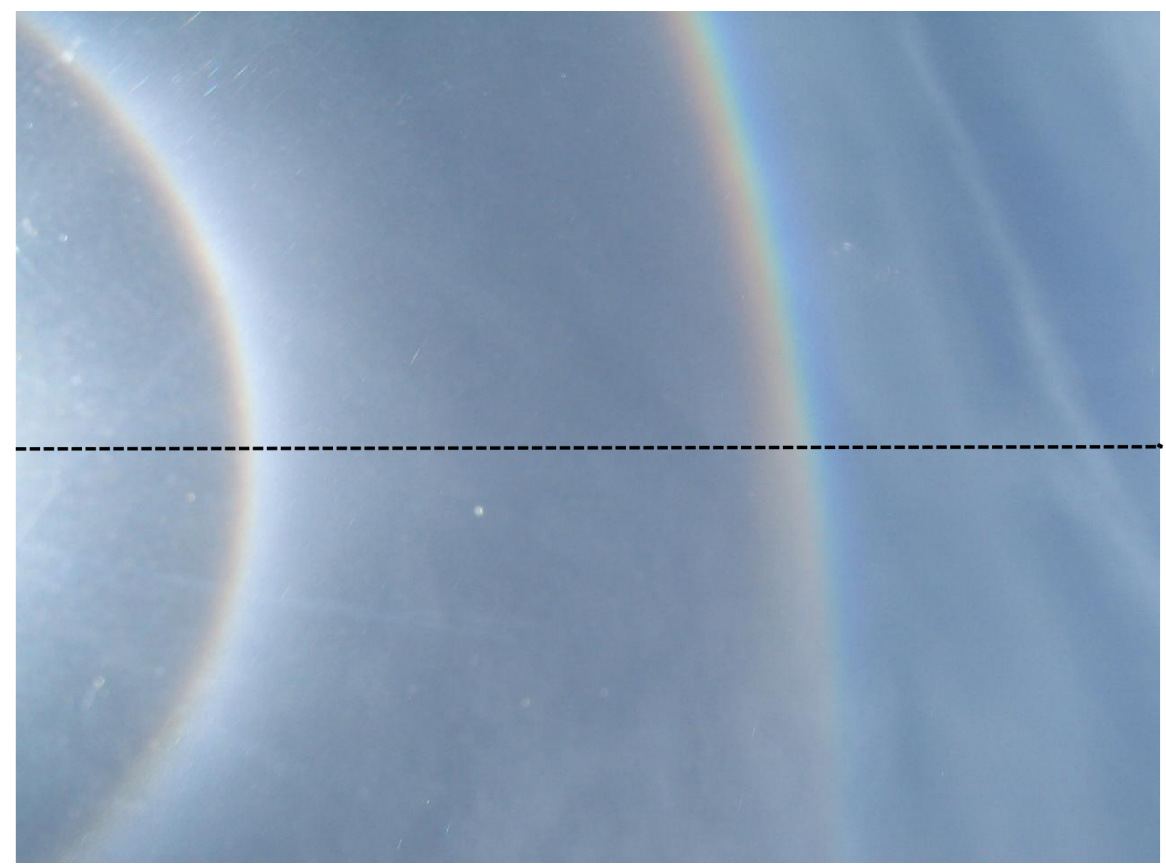

\section{Halos and ice crystals}

T. J. Garrett et al.

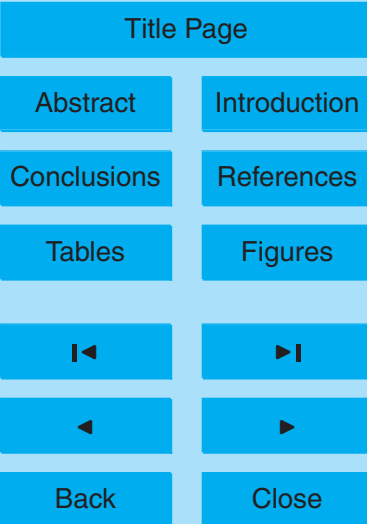

Fig. 5. Photograph of $22^{\circ}$ and $46^{\circ}$ halos taken from the WB-57F at 19:00 UTC on 22 April, 2004 at $9.85 \mathrm{~km}$ altitude, when the solar zenith angle was $17^{\circ}$. A cross-section of image intensity along the azimuth (dashed line) is shown in Fig. 6.

\section{Full Screen / Esc}

Printer-friendly Version

Interactive Discussion

\section{EGU}




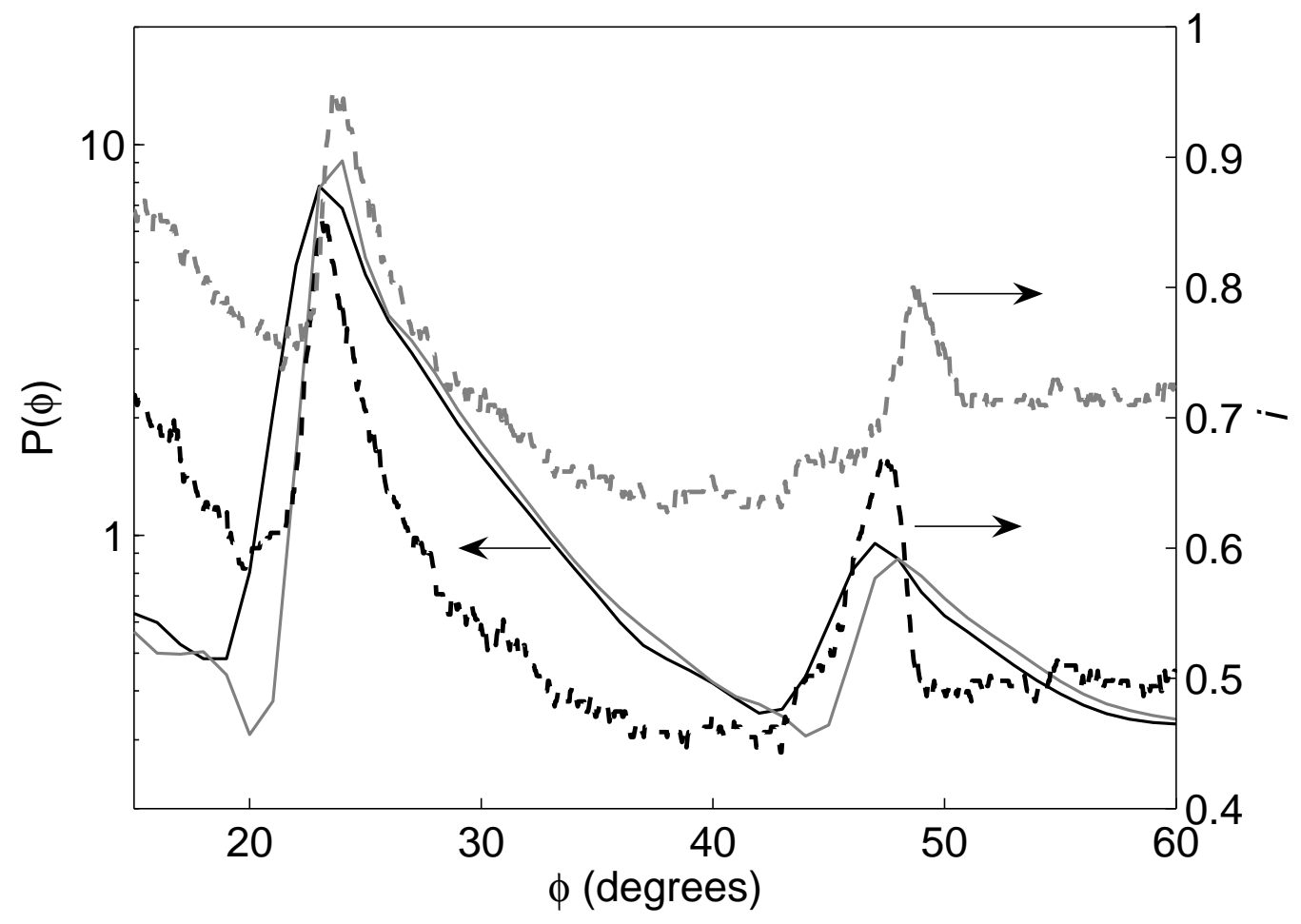

Fig. 6. Normalized intensity cross-sections ( $i$; right axis) of red (dashed black) and blue (dashed gray) pixels along the dashed cross-section in Fig. 5. Corresponding phase functions for $16 \mu \mathrm{m} r_{e q}$ column ice crystals are superimposed on the image (solid line; left axis).

\section{ACPD}

7, 1295-1325, 2007

Halos and ice crystals

T. J. Garrett et al.

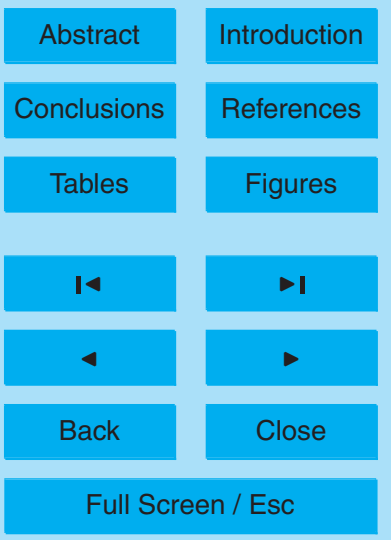

Printer-friendly Version

Interactive Discussion 


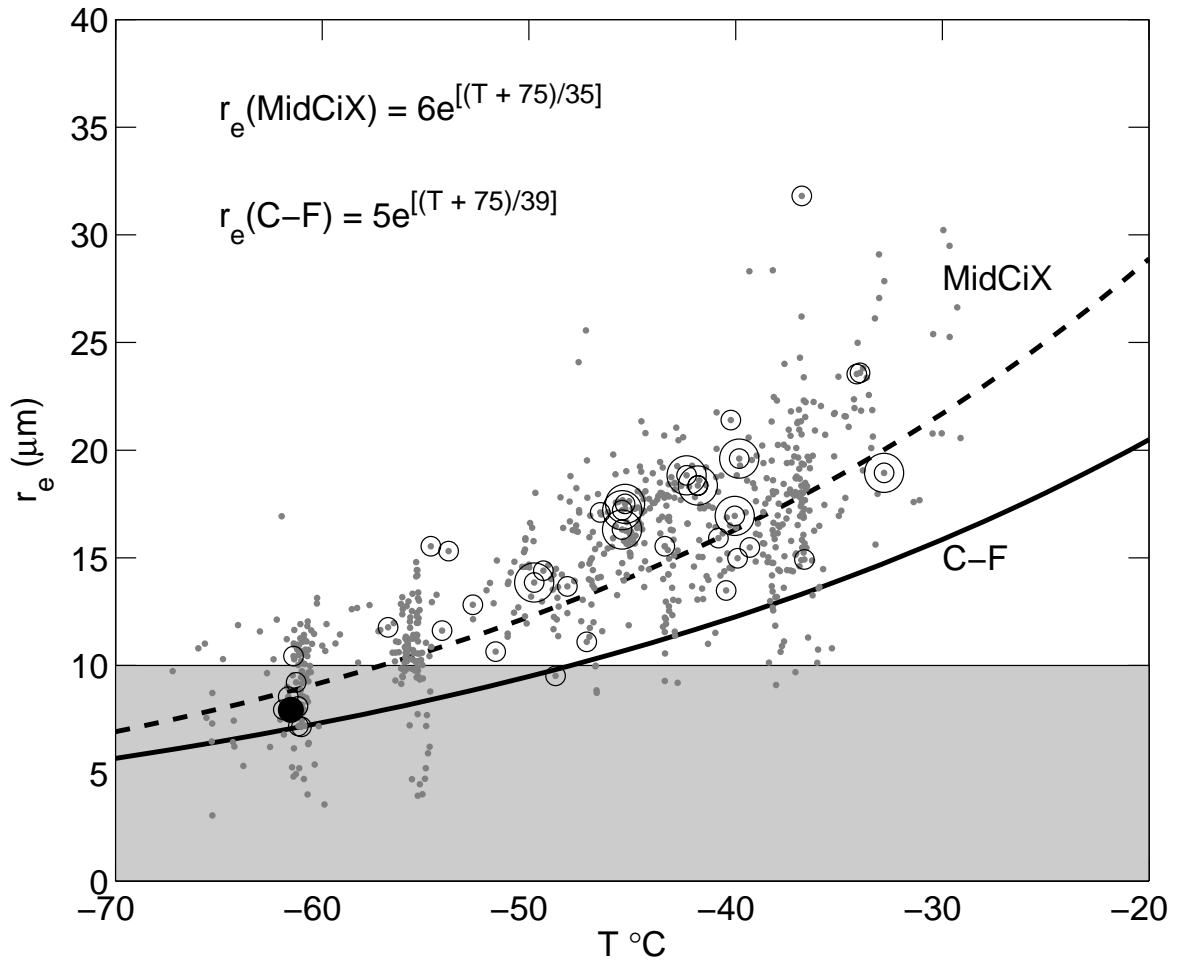

Fig. 7. Thirty-second mean values of ice crystal effective radius $r_{e}$ obtained using bulk $\beta_{\text {ext }}$ and IWC data during MidCiX. Data points explicitly noted by the WB-57F back-seater as being associated with $22^{\circ}$ and $46^{\circ}$ halos, are marked with single and double circles, respectively. The black dot corresponds to the photograph in Fig. 8. The gray box represents the region below which, theoretically, it should be expected that diffraction effects would begin to smooth out a distinct halo. A fit to the MidCiX data is shown by the dashed line. A fit (solid line) to the CRYSTAL-FACE data set (C-F) as described by Garrett et al. (2003) is shown for comparison.
ACPD

7, 1295-1325, 2007

Halos and ice crystals

T. J. Garrett et al.

Title Page

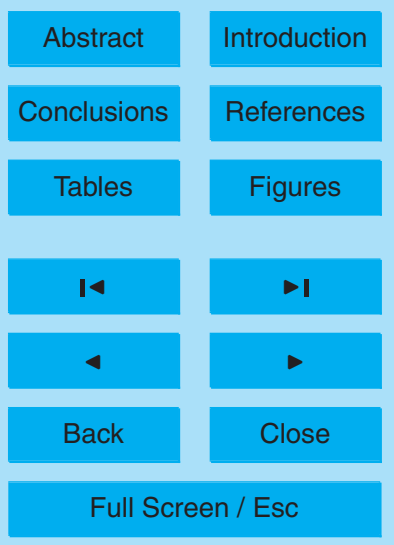

Printer-friendly Version

Interactive Discussion 


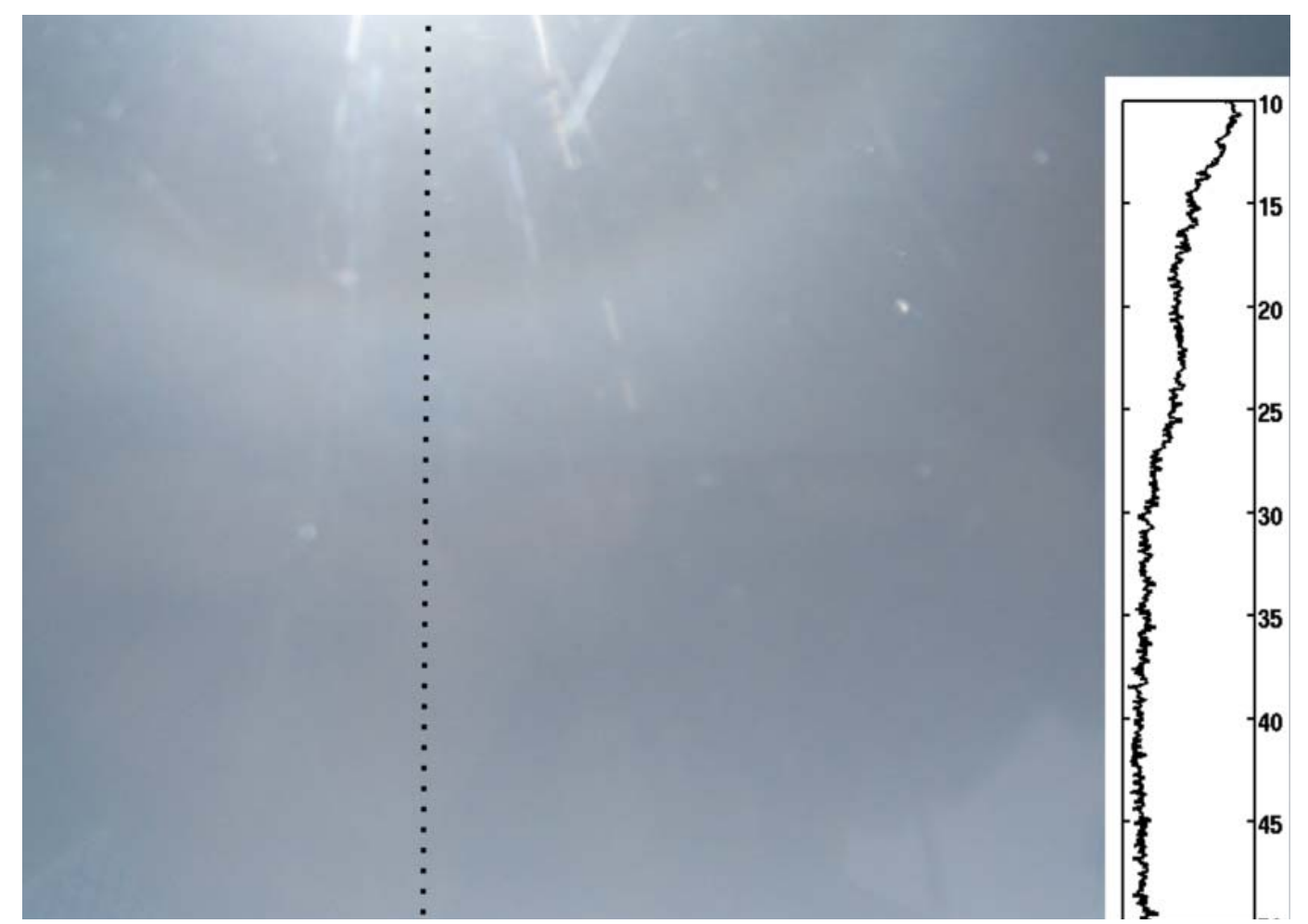

Fig. 8. Photograph of a $22^{\circ}$ halo taken on 19 July at $19: 17$ UTC at $12.1 \mathrm{~km}$ altitude, less than $100 \mathrm{~m}$ below local cloud top, and corresponding to the black point in Fig. 7. A pixel intensity profile along the dashed line (linear scale) is shown within the inset.
ACPD

7, 1295-1325, 2007

Halos and ice crystals

T. J. Garrett et al.

Title Page

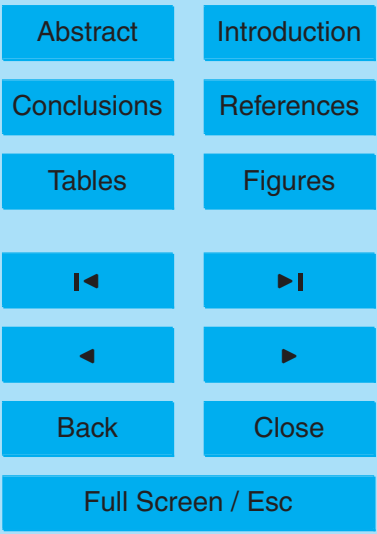

Printer-friendly Version

Interactive Discussion 